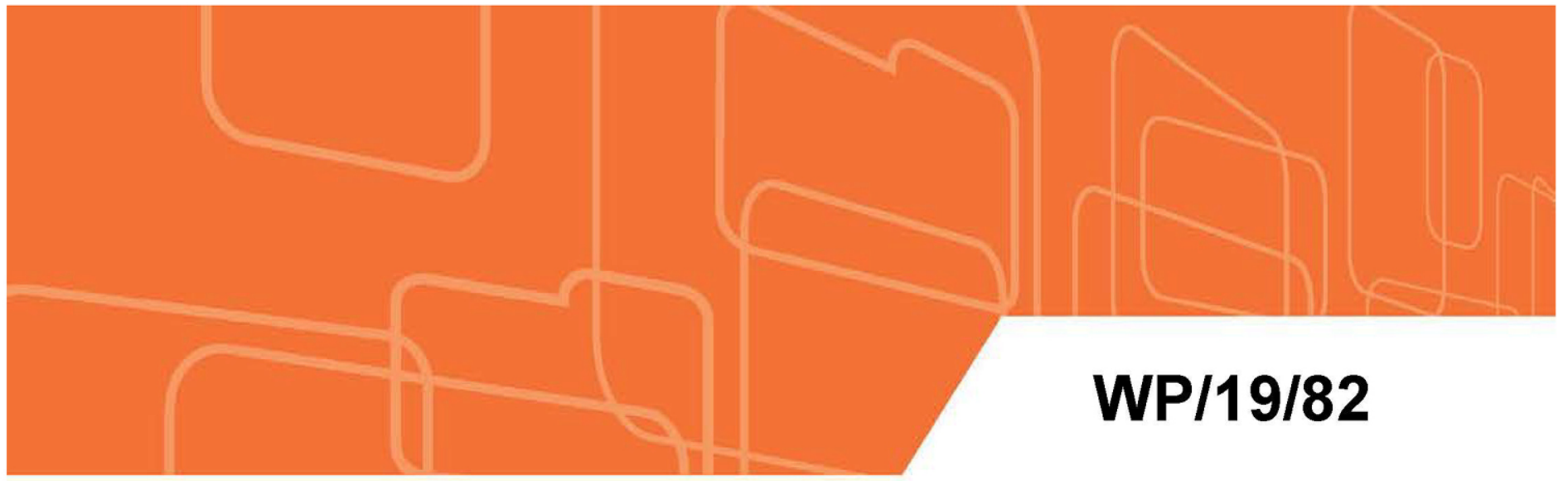

IMF Working Paper

\title{
Global Declining Competition
}

By Federico J. Díez, Jiayue Fan, and Carolina Villegas-Sánchez

IMF Working Papers describe research in progress by the author(s) and are published to elicit comments and to encourage debate. The views expressed in IMF Working Papers are those of the author(s) and do not necessarily represent the views of the IMF, its Executive Board, or IMF management. 


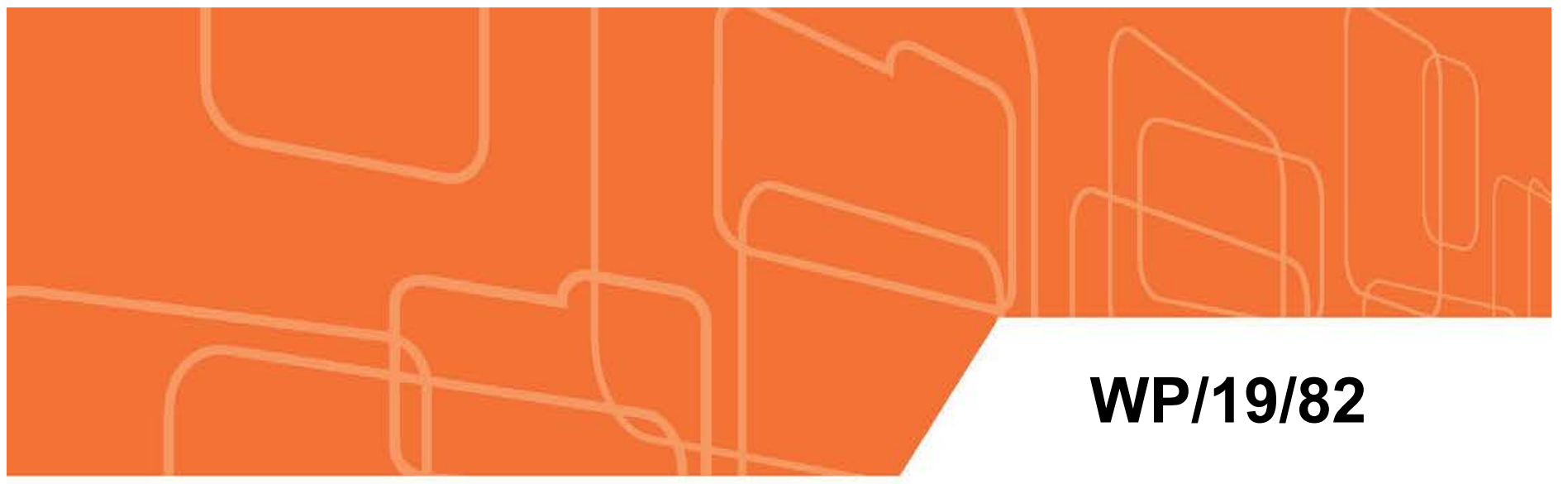

\section{IMF Working Paper}

\section{Global Declining Competition}

By Federico J. Díez, Jiayue Fan, and Carolina Villegas-Sánchez

IMF Working Papers describe research in progress by the author(s) and are published to elicit comments and to encourage debate. The views expressed in IMF Working Papers are those of the author(s) and do not necessarily represent the views of the IMF, its Executive Board, or IMF management.

$$
\text { I N T E R N A T I O N A L M O N E T A R Y }
$$




\title{
IMF Working Paper
}

Research Department

\section{Global Declining Competition*}

\section{Prepared by Federico J. Díez, Jiayue Fan, and Carolina Villegas-Sánchez}

Authorized for distribution by Romain Duval

April 2019

\section{IMF Working Papers describe research in progress by the author(s) and are published to elicit} comments and to encourage debate. The views expressed in IMF Working Papers are those of the author(s) and do not necessarily represent the views of the IMF, its Executive Board, or IMF management.

\begin{abstract}
Using a new firm-level dataset on private and listed firms from 20 countries, we document five stylized facts on market power in global markets. First, competition has declined around the world, measured as a moderate increase in average firm markups during 20002015. Second, the markup increase is driven by already high-markup firms (top decile of the markup distribution) that charge increasing markups. Third, markups increased mostly among advanced economies but not in emerging markets. Fourth, there is a non-monotonic relation between firm size and markups that is first decreasing and then increasing. Finally, the increase is mostly driven by increases within incumbents and also by market share reallocation towards high-markup entrants.

JEL Classification Numbers: D2, D4, E2, F6, L1, L4

Keywords: Markups, Market power, TFP, Firm size

Author's E-Mail Address: fdiez@imf.org, jfan@imf.org, and carolina.villegas@esade.edu.

*We are grateful to Pol Antràs, Gianluca Benigno, Camila Casas, Romain Duval, Emmanuel Farhi, and Sebnem Kalemli-Ozcan for useful comments and suggestions. Villegas-Sánchez thanks Banco Sabadell and AGAURGeneralitat de Catalunya for financial support. The views expressed in the paper are those of the authors and do not necessarily represent the views of the IMF, its Executive Board, or IMF management.
\end{abstract}




\section{Contents}

1 Overview $\quad \underline{4}$

2 Measuring Market Power $\quad \underline{8}$

3 Data $\quad \underline{11}$

4 Baseline Results $\quad \underline{12}$

4.1 High-markup Firms . . . . . . . . . . . . . . . . . . . $\underline{15}$

5 Extensions and Robustness Analysis $\quad \underline{16}$

5.1 Digital Economy . . . . . . . . . . . . . . . . . . . $\underline{16}$

5.2 Alternative Panel and Geographical Disparities . . . . . . . . . . . . . $\underline{17}$

5.3 Alternative Specification and Methodology . . . . . . . . . . . . . . $\underline{18}$

5.3 .1 Rolling Window . . . . . . . . . . . . . . . . 19

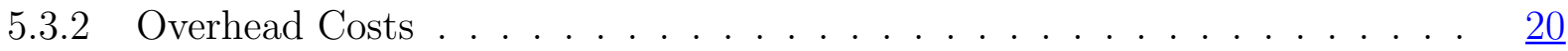

5.3.3 Production Function Estimation . . . . . . . . . . . . . . 20

5.3 .4 Choice of Flexible Input . . . . . . . . . . . . . . . . . 21

6 Markups and Size $\quad \underline{23}$

6.1 Cross-Sectional Decomposition . . . . . . . . . . . . . . . . . $\underline{23}$

6.2 A U-Shaped Relationship . . . . . . . . . . . . . . . . . . $\underline{24}$

6.3 Dynamic Decomposition with Firm Entry and Exit . . . . . . . . . . . . . $\underline{27}$

7 Conclusion $\quad \underline{30}$

A Data $\quad \underline{35}$

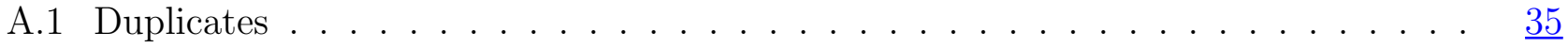

A.2 Data Cleaning . . . . . . . . . . . . . . . . . . $\underline{35}$

B Additional Results $\quad \underline{38}$

C Dynamic OP Decomposition with Entry and Exit $\quad \underline{40}$ 


\section{List of Figures}

1 Average Global Markup . . . . . . . . . . . . . . . . . $\underline{14}$

2 High-markup, Middle, and Laggard Firms . . . . . . . . . . . $\underline{15}$

3 Average Markups, ICT-Intensive vs All firms . . . . . . . . . . . . . . . . $\underline{18}$

4 Advanced Economies vs Emerging Markets . . . . . . . . . . . . . . . 19

5 Markups: Robustness Analysis . . . . . . . . . . . . . . . $\underline{22}$

6 Markup and Firm Size: Unconditional Correlation . . . . . . . . . . . $\underline{23}$

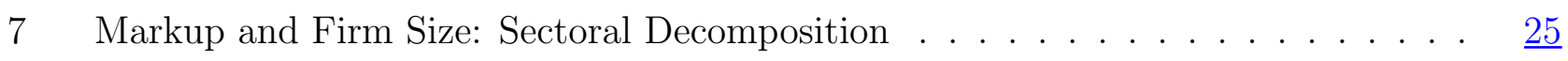

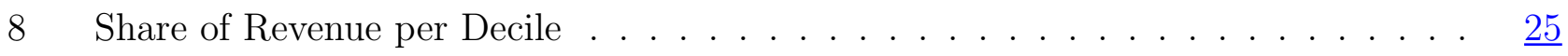

B.1 Markup Increase by Weighting Scheme $\ldots \ldots \ldots \ldots \ldots$

B.2 Increase in Profitability . . . . . . . . . . . . . $\underline{38}$

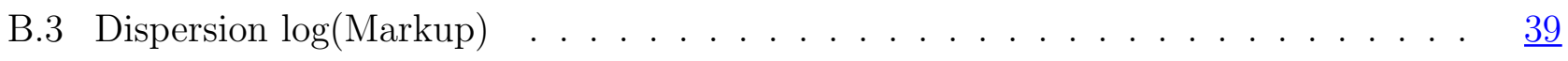

\section{List of Tables}

1 List of Countries in Samples . . . . . . . . . . . . . . . $\underline{13}$

2 Summary Statistics . . . . . . . . . . . . . . . $\underline{13}$

3 High-markup firms by Sector . . . . . . . . . . . . . . 17

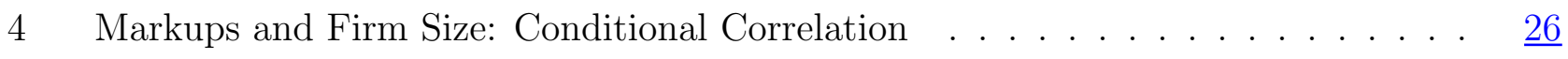

$5 \quad$ Dynamic Firm Markup Decomposition 2000-2015 . . . . . . . . . . . . . $\underline{29}$

B.1 Markups and Firm Size: Conditional Correlation $\ldots \ldots \ldots \ldots$ 


\section{Overview}

Market power is back at the center of policy and academic discussions. Indeed, there is some popular concern that the world economy may be entering a new Gilded Age, characterized by a decline in competition and the rise of monopolies that generate resource misallocation, welfare losses and inequality. On the academic front, much of the discussion was spurred by recent work that documented a decline in competition in the United States and linked it to several macroeconomic phenomena affecting the U.S. economy like the decline in the labor share, low investment, and the reduction in new business formation (Council of Economic Advisers (2016), De Loecker and Eeckhout (2017), Gutiérrez and Philippon (2017)).

In this paper we present new evidence on market power and we provide an overview of the degree of competition in markets around the world. Specifically, we compute markups for firms, publicly listed and privately held, from 20 countries, advanced and emerging. As we explain in detail below, there is substantial markup heterogeneity not only across different groups of countries but also between firms within any given industry and between different parts of the firm size distribution. Therefore, both of these aspects are crucial to properly understand the recent dynamics of competition in the global economy. ${ }^{1}$ In particular, we document the following stylized facts that we further develop in the rest of the paper:

(F1) Global markups have increased by 6 percent between 2000 and 2015 .

(F2) The increase in markups is mostly explained by the behavior of high-markup firms. ${ }^{2}$

(F3) The increase in markups is concentrated in advanced economies.

(F4) There is a non-monotonic (U-shaped) relationship between firm size and markups.

(F5) The increase in markups is mostly explained by within-firm increases among incumbent firms and, to a lower extent, by market share reallocation towards high-markup entrants. ${ }^{3}$

\footnotetext{
${ }^{1}$ Díez et al. (2018) and De Loecker and Eeckhout (2018) also compute global market power measures based on large sets of countries. However, they use data only on publicly listed firms.

${ }^{2}$ High-markup firms are defined as the top decile of firms ranked according to their markups.

${ }^{3}$ It should be noted that this finding holds for the overall sample. However, in the case of the United States, we find that most of the increase in markups is actually explained by the reallocation effect, that is, by high-markup firms becoming relatively larger, something in line with the findings on superstar firms by Autor et al. (2017).
}

CInternational Monetary Fund. Not for Redistribution 
We start by documenting a global decline in competition, measured by markups that have increased by 6 percent between 2000 and 2015. ${ }^{4}$ This average increase, however, masks great heterogeneity at different levels. One the one hand, we document stark differences across geographical regions, with markups especially increasing among advanced economies but not as much among emerging markets. On the other hand, the markup increase is mostly explained by the behavior of a small fraction of high-markup firms (the top decile of the markup distribution), whose markups increased 40 percent, in contrast to firms in the bottom half of the markup distribution that show stagnant markups - both facts translate into a significant increase in markup dispersion. Furthermore, these high-markup firms are spread economy-wide across all sectors (although they are more likely to be found in sectors that use digital technologies more intensively), implying substantial within-sector markup heterogeneity.

Given the importance of high-markup firms in the evolution of global markups, we explore in detail the relation between firm size and markups to assess its quantitative importance. Contrary to common wisdom, we find that unconditionally, smaller firms have higher markups, even within narrowly defined industries - only when we focus on the top 5 percentile of the distribution of firm sales do we find a positive relation. However, conditional on firm observable characteristics, we find a non-monotonic (U-shaped) relationship between firm size and markups both in the cross-section and in the within firm time-variation, reconciling with the fact, found in previous studies based on listed firms only, that the largest firms tend to have higher markups. Both findings unveil a (to the best of our knowledge) new stylized fact: markups first decrease as firm size increases and only when a (fairly large) size threshold is reached, do markups start increasing with firm size. In line with this, we also find that the group of high-markup firms, while including some few large firms, is mostly composed of rather small firms - these are likely firms operating in niche markets, facing demands that allow them to charge high markups.

To assess the relative importance of different drivers (i.e., changes within vs reallocation across firms) in the overall markup increase, we conduct a decomposition à la Melitz and Polanec (2015).

\footnotetext{
${ }^{4}$ One could look at measures of concentration (like the Herfindahl index or the concentration ratio) as alternative measures of market power. However, concentration measures are necessarily constructed at the industry level which prevents from exploring intra-industry heterogeneity. In addition, antitrust authorities for example, typically focus on more granular measures of concentration than what would be available for broad cross-country comparisons. In addition, an increase in competition can sometimes lead to an increase in concentration (Syverson (2018), Van Reenen (2018)).
} 
We find that most of the aggregate increase in markups is driven by within-firm increases of incumbent firms and, to a smaller degree, by successful new high-markup firms. Once again, we find somewhat different results when we focus on firms at the top 5 percent of the sales distribution. For these firms, the markup increase is driven mainly by the market share reallocation effect among incumbent firms and new entrants - something in line with the findings for the United States.

Finally, the paper also shows that the main results are robust to different production function specifications and estimation techniques. Specifically, we find that the moderate increase in markups is also observed if we use a rolling-window estimation to allow for time-varying elasticities, if we estimate a translog production function (instead of the baseline Cobb-Douglas), or if estimate the production function using the the inverse-share method of Gandhi et al. (2017) instead of the traditional control function approach. We also highlight the importance of the choice of the input used for the markup computation, where the use of materials tends to generate larger increases than the commonly used cost of goods sold.

The paper is related to a burgeoning literature on firms' market power and its macroeconomic effects. De Loecker and Eeckhout (2017) estimate a sharp increase of markups in the Unites States, and link it to several macroeconomic phenomena, including declines in the labor share, the labor participation rate, and aggregate output growth. Hall (2018) provides evidence of heterogeneous increases in market power in US industries and some evidence that growth of high-markup mega-firms is associated with rising market power in the U.S.. Gutiérrez and Philippon (2017) document a significant increase in market power by firms in the United States (measured as higher concentration rates) and how this has negative macroeconomic consequences like, for instance, lower investment. Díez et al. (2018), document an increase in global markups and find evidence of a non-monotonic (inverted U-shaped) relation between markups and investment with a sizable fraction of firms currently located at markup levels such that further increases are associated with lower investment rates. Baqaee and Farhi (2017) develop a model for aggregating microeconomic shocks and find that the elimination of markups in the United States would increase total factor productivity (TFP) by 20 percent. Edmond et al. (2018) calibrate a model and estimate the different costs of markups; the main costs being that the aggregate markup acts as a tax on output and the generated misallocation of inputs. ${ }^{5}$ Finally, differences in the institutional setting have

\footnotetext{
${ }^{5}$ Other related work includes Barkai (2017) that estimates a rise in the aggregate markup for the U.S. private
} 
been proposed as a potential source of the observed declined in competition with important implications for productivity growth. Gutiérrez and Philippon (2018) document lower concentration measures in European markets compared to the U.S. and provide evidence on differences in the independence of antitrust authorities to rationalize their findings. Akcigit et al. (2018), focusing on Italy, show that market leaders are more likely to be politically connected, which in turn translates into higher rates of survival, growth in employment and revenue, but interestingly, not in higher productivity or innovation. Van Reenen (2018) provides an overview of alternative explanations to differences in antitrust enforcement, namely globalization and technological change, to explain the observed increase in market power.

We contribute to this literature in several aspects. First, we highlight the importance of looking at the entire distribution of firms, including privately-held ones, to assess the actual level of competition in a market and most importantly, better assess the macroeconomic relevance and implications. In contrast, most of the literature focuses on publicly traded firms thereby missing sizable portions of the firm distribution. ${ }^{6}$ We find markup increases significantly lower than studies based on listed firms only; our results show that the increase in markups is driven by high-markup firms which include both listed and private firms - it follows that looking to both types of firms is critical to understand the economy-wide macro implications. Second, most of the attention thus far has been concentrated on U.S. listed firms while our analysis is based on a broad world-wide coverage, including emerging markets. ${ }^{7}$ Finally, we also contribute to the literature by unveiling the non-monotonicity (U-shaped) between markups and firm size, a previously unknown stylized fact.

The rest of the paper is organized as follows. In Section 2 we discuss the methodological issues around markup estimation. In Section 3 we describe our dataset. In Section 4 we present our baseline results on global market power. Section 5 presents our robustness analysis and highlights the caveats to be considered in interpreting markups. Section 6 presents evidence on the link

sector while explaining the decline in the labor and capital shares. Eggertsson et al. (2018) develop a model to explain how increased market power together with a decreased natural rate of interest can explain recent puzzling macroeconomic facts, including an increase in Tobin's Q permanently above 1, a decrease in the ratio of investment to output, and declines in the labor and capital shares.

${ }^{6}$ To the best of our knowledge, Calligaris et al. (2018) is the only other paper looking at private firms across countries - but the focus is on the effects of the digital economy on markups and not the relationship with size.

${ }^{7}$ One early study extending the analysis to European countries is Gutiérrez and Philippon (2017). Recently, Díez et al. (2018), De Loecker and Eeckhout (2018) and Karabarbounis and Neiman (2018) have provided additional evidence on listed companies for a wider set of countries.

CInternational Monetary Fund. Not for Redistribution 
between market power and size. Finally, Section 7 concludes.

\section{Measuring Market Power}

Market power is the ability to create a wedge between prices and marginal costs (Tirole 1988). Therefore, markups, defined as the ratio of price to marginal cost, are a direct measure of market power. $^{8}$

While the definition of markups is a very clear economic concept, its estimation is not as straightforward. The reason is that firm prices and marginal costs are two variables that are often not observable in most firm-level databases. Rather than focusing on the demand side to estimate markups, Hall $(1986,1988)$ proposed an alternative approach. His insight is based on the observation that under perfect competition and constant returns to scale, markups will be equal to one. ${ }^{9}$ De Loecker and Warzynski (2012) build on this early work to derive estimates of firm-level markups from the cost minimization problem of the firm. Their contribution is twofold. First, the markup expression is derived at the firm level. Second, based on recent advancements in the industrial organization literature, input elasticities are estimated following the control function approach (see Ackerberg et al. (2015) for a review). In particular, for any production function $\mathcal{F}_{i t}(\cdot)$, De Loecker and Warzynski (2012) derive the following expression for the firm markup from the cost-minimization first-order condition:

$$
\mu_{i t} \equiv \frac{P_{i t}}{M C_{i t}}=\underbrace{\frac{\partial \mathcal{F}_{i t}(\cdot)}{\partial \mathcal{V}_{i t}} \frac{\mathcal{V}_{i t}}{\mathcal{F}_{i t}(\cdot)}}_{\text {OutputElasticity }} / \underbrace{\frac{P_{i t}^{\mathcal{V}_{i t}} \mathcal{V}_{i t}}{P_{i t} Q_{i t}}}_{\text {ExpenditureShare }}=\frac{\beta_{i t}^{\mathcal{V}}}{\alpha_{i t}^{\mathcal{V}}},
$$

where $\mu_{i t}$ is the markup, $P_{i t}$ is the output price, $M C_{i t}$ is marginal cost, $\mathcal{V}_{i t}$ refers to any flexible

\footnotetext{
${ }^{8}$ The link between market power and markups is further corroborated by the fact that, in the data, increases in markups are also associated with increases in profits beyond any potential increase in overhead costs. See De Loecker and Eeckhout (2017) and Díez et al. (2018).

${ }^{9}$ Hall (1986) derives the following expression:

$$
\Delta q=\mu \alpha \Delta n+\varpi+u
$$

where $\Delta q$ is the rate of change in output, $\Delta n$ is the rate of change in labor, $\mu$ is the markup, $\alpha$ is the labor share in revenue, $\varpi$ is the average rate of technological change, and $u$ is the error term. Rearranging, the rate of change in output over the rate of change in labor is the labor elasticity and therefore, the markup equals the ratio between labor elasticity of output and the labor revenue share. The main difficulty in this exercise lies in obtaining an unbiased estimate of the input elasticity. Hall (1986) proposes various instrumental variables and Klette (1999) follows a similar approach using GMM estimation.
} 
input, and $P_{i t} Q_{i t}$ is nominal sales. In sum, the firm markup can be estimated as the ratio of the output elasticity of a variable input $\left(\beta_{i t}^{\mathcal{V}}\right)$ to the firm expenditure share on that input $\left(\alpha_{i t}^{\mathcal{V}}\right)$. Expenditure shares can be directly obtained from any dataset containing firm-level information on sales and input expenditure. However, the output elasticity is not directly observable and requires estimation.

Firm-level estimates of the output elasticity cannot be easily obtained but, under the assumption that all firms within a sector share the same technology, it is possible to estimate the following industry-specific Cobb-Douglas production function: ${ }^{10}$

$$
q_{i t}=\beta_{\nu} \nu_{i t}+\beta_{k} k_{i t}+\omega_{i t}+\epsilon_{i t}
$$

where lower cases denote logs, $q_{i t}$ represents the log of real sales, $\nu_{i t}$ is the log of any flexible input (in real terms), $k_{i t}$ refers to the log of the real capital stock, $\omega_{i t}$ stands for firm productivity and $\epsilon_{i t}$ is the error term including unanticipated productivity shocks and measurement error. The traditional estimation challenge to obtain consistent estimates of the output elasticities is simultaneity bias, due to the likely possibility that the firm-productivity (unobserved to the econometrician but known to the firm) is correlated with the input choice. As De Loecker and Warzynski (2012), we follow the control function approach literature pioneered by Olley and Pakes (1996) and Levinsohn and Petrin (2003) and recently updated by Ackerberg et al. (2015). The methodology assumes that productivity follows a first-order Markov process and is a function of the firm's flexible inputs and capital: $\omega_{i t}=h\left(\nu_{i t}, k_{i t}\right)$. ${ }^{11}$ Then the method proceeds in two steps. In the first step, one obtains estimates of the expected output that removes measurement error and unanticipated shocks:

$$
q_{i t}=\phi_{t}\left(\nu_{i t}, k_{i t}\right)+\epsilon_{i t},
$$

\footnotetext{
${ }^{10}$ We follow De Loecker and Eeckhout (2017) and we first consider a Cobb-Douglas production function with only one flexible input, the cost of goods sold (COGS). Both assumptions are later relaxed with a translog production function and multiple flexible inputs.

${ }^{11}$ Olley and Pakes (1996) use the investment decision to proxy for unobserved productivity while Levinsohn and Petrin (2003) rely on intermediate inputs to proxy for unobserved productivity - the proxy functions. Provided the monotonicity condition is met and intermediate inputs are strictly increasing in $\omega_{i t}$, the proxy function can be inverted, allowing to express the unobserved productivity as a function of observable characteristics. De Loecker and Warzynski (2012) argue that the monotonicity of intermediate inputs in productivity holds under a large class of models of imperfect competition.
} 
In particular, estimates of expected output are obtained from the following second-order approximation:

$$
\phi_{i t}=\beta_{\nu} \nu_{i t}+\beta_{k} k_{i t}+\beta_{\nu \nu} \nu_{i t}^{2}+\beta_{k k} k_{i t}^{2}+\beta_{\nu k} \nu k_{i t}+h\left(\nu_{i t}, k_{i t}\right)
$$

For the second stage, the method relies on the law of motion for productivity, which is assumed to be: $\omega_{i t}=g_{t}\left(\omega_{i, t-1}\right)+\xi_{i t}$, where $\xi_{i t}$ are the innovation shocks to productivity and the estimates are obtained by projecting productivity on its lagged value. ${ }^{12}$ Based on these steps, the following moment conditions can be formed to obtain the output elasticity estimates:

$$
E\left(\xi_{i t}(\beta)\left(\begin{array}{c}
\nu_{i, t-1} \\
k_{i, t}
\end{array}\right)\right)=0
$$

Notice the moment condition for the flexible input uses $\nu_{i, t-1}$ as an instrument and addresses the Ackerberg et al. (2015) critique. $^{13}$ This means the firm chooses the flexible input after the capital stock was determined at time $t-1$. Recent work by Gandhi et al. (2017) questions this identification of the output elasticity when the flexible input of the production function is also used as the proxy function. In Section 5 we re-estimate the markups using the methodology proposed by Gandhi et al. (2017), instead.

The production function is estimated separately by industry (2-digit NACE Rev.2 industry classification), obtaining a different output elasticity by sector so that the final firm-level markup is obtained as:

$$
\mu_{i t}=\frac{\beta_{s}^{\nu}}{\alpha_{i t}^{\nu}}
$$

where $\beta_{s}^{\nu}$ is the output elasticity of the flexible input $\nu$ in industry $s$ and $\alpha_{i t}^{\nu}$ is the expenditure share of flexible input $\nu$ by firm $i$ in period $t .{ }^{14}$ According to equation (6), markups are the deviation between the elasticity of output with respect to a variable input and that input's share of total revenue.

\footnotetext{
${ }^{12}$ In practice we project productivity on a third order polynomial of lagged productivity.

${ }^{13}$ Ackerberg et al. (2015) argue that in the traditional Levinsohn and Petrin (2003) approach to estimate a production function using labor, materials and capital inputs, if labor was a function of both productivity and capital, it would not be possible to identify the coefficient on labor in the first stage.

${ }^{14}$ The expenditure share is the ratio of the cost of flexible input $\nu$ to sales where sales are corrected for the presence of measurement error as suggested by De Loecker and Warzynski (2012).
} 


\section{Data}

The main data source of the paper is Orbis, provided by Bureau van Dijk. Orbis contains information on around 300 million companies across the globe. Its main strength lies in the availability of harmonized cross-country financial information for both private and public firms since the mid90s. Bureau van Dijk gathers data from over 160 providers (usually local companies that collect information from the business registers). Our data were obtained through the "Orbis Historical" product that provides the longest available coverage. ${ }^{15}$

The "raw" data requires intensive cleaning prior to estimation. The cleaning procedure closely follows Kalemli-Özcan et al. (2015), Gopinath et al. (2017) and Gal (2013). Appendix A details the cleaning steps which first involve dealing with basic reporting mistakes (i.e., negative sales, total assets, employment, cost of employees, tangible fixed assets or liabilities; missing or zero values for the cost of materials, operating revenue, total assets and missing NACE sectoral code). Second, we implement further quality checks that verify the age of the firm, the ratio of shortterm to long-term liabilities, the ratio of employees to capital, tangible fixed assets to total assets, capital to shareholder funds, and total assets to shareholder funds. Finally, we apply filters on the annual growth rates of sales, operating revenues and number of employees by company size category.

When pooling data across countries we use PPP-adjusted sector deflators. The data set includes information from all sectors of the economy and one of the main challenges is to find 2-digit industry producer price indexes across countries. We compiled information on value added and gross output deflators from various sources, including the OECD, Eurostat and government websites, and used the ones that had better coverage across industries and time. ${ }^{16}$ When available we used the 2-digit NACE deflator; this was the case for most sectors in European countries and for manufacturing sectors in most other countries. In the absence of 2-digit deflators we used 1-digit NACE industry deflators and in the absence of disaggregated industry deflators we used the overall country GDP deflator. Finally, we follow Inklaar and Timmer (2014) and PPP-adjust the deflators to take care of the cross-country sectoral differences in price levels. Consequently,

\footnotetext{
${ }^{15}$ See Kalemli-Özcan et al. (2015) on how to recover the longest historical series from various disk vintages instead.

${ }^{16}$ For consistency, we do not mix sources within a country or over time.
} 
firm turnover revenue, wage bill, material costs and cost of goods sold are expressed in U.S. dollars of 2005. Capital is deflated using the WDI PPI adjusted exchange rate to convert into dollars of 2005. Finally, to avoid concerns about the representativeness and comparability of the sample across countries, we focus on the sample of firms with average employment greater or equal to 20 employees. ${ }^{17}$

Table 1 presents the list of countries included in our data set. Ultimately, we have a baseline sample with data on 20 countries for the period 2000-2015 and an alternative sample on 28 countries for 2004-2013. ${ }^{18}$ Specifically, the baseline sample includes Belgium, Bulgaria, Denmark, Estonia, Finland, France, Great Britain, Greece, Hungary, Italy, Japan, Latvia, Netherlands, Poland, Portugal, Romania, Russia, Slovenia, Spain and the United States. The alternative sample includes, in addition, Austria, China, Czech Republic, Germany, Ireland, Korea, Slovakia, and Turkey. Our baseline sample consists of over 5 million observations with an average annual income of 55 million U.S. dollars. In addition, the average firm has 194 employees, incurs in sales' costs (directly attributable to production, COGS) of $\$ 40$ million, and possesses capital (proxied by tangible fixed assets) by almost $\$ 20$ million. ${ }^{19}$ Table 2 shows the summary statistics of the main variables used in the estimation of TFP.

\section{Baseline Results}

We begin by computing the evolution of the average markup pooling all countries in our sample. For this, we compute the markup at the firm level, following equation (6), and aggregate up weighting each firm by its sales. ${ }^{20}$ We present the resulting aggregate markup in Figure 1, where we can observe that, from a global perspective, markups have increased around 6 percent during

\footnotetext{
${ }^{17}$ The 20-employee threshold improves the coverage within a country and the comparability across countries. In addition, we initially selected the set of countries for which aggregate Orbis data represented at least $40 \%$ of the total output reported in official sources. The United States is included in the sample despite a lower coverage in some years due to its relevance in the global economy.

${ }^{18}$ Data limitation in the time series coverage for some countries, results in an alternative sample that is shorter but wider, covering 28 countries over 20042013.

${ }^{19}$ Monetary values are expressed in U.S. dollars of 2005.

${ }^{20}$ In Figure B.1 in Appendix B we show that the moderate increase in average markups is robust to alternative weighting schemes, including costs - Edmond et al. (2018), based on their model, use cost weights instead of sales and argue that this generates a lower increase in the resulting aggregate markup.
} 
Table 1: List of Countries in Samples

\begin{tabular}{|c|c|c|c|}
\hline \multicolumn{2}{|c|}{ Baseline Sample } & \multicolumn{2}{|c|}{ Alternative Sample } \\
\hline Country & Coverage & Country & Coverage \\
\hline Belgium & $2000-2015$ & Austria & $2004-2013$ \\
\hline Bulgaria & $2000-2015$ & China & 2004-2013 \\
\hline Denmark & $2000-2015$ & Czech R. & 2004-2013 \\
\hline Estonia & $2000-2015$ & Germany & $2004-2013$ \\
\hline Finland & $2000-2015$ & Ireland & 2004-2013 \\
\hline France & $2000-2015$ & Korea & 2004-2013 \\
\hline Great Britain & $2000-2015$ & Slovakia & 2004-2013 \\
\hline Greece & $2000-2015$ & Turkey & 2004-2013 \\
\hline Hungary & $2000-2015$ & & \\
\hline Italy & $2000-2015$ & & \\
\hline Japan & $2000-2015$ & & \\
\hline Latvia & $2000-2015$ & & \\
\hline Netherlands & $2000-2015$ & & \\
\hline Poland & $2000-2015$ & & \\
\hline Portugal & $2000-2015$ & & \\
\hline Romania & $2000-2015$ & & \\
\hline Russia & $2000-2015$ & & \\
\hline Slovenia & $2000-2015$ & & \\
\hline Spain & $2000-2015$ & & \\
\hline United States & $2000-2015$ & & \\
\hline
\end{tabular}

Notes: The baseline sample includes countries with financial information during the period 20002015. The alternative sample includes all countries listed in the table, with the countries from the baseline sample extending over a shorter time span (2004-2013).

Table 2: Summary Statistics

\begin{tabular}{lcccc} 
& Turnover & Capital & Costs of goods sold & Employment \\
\hline Mean & $55,567,404$ & $19,267,384$ & $39,561,494$ & 194 \\
P50 & $5,536,489$ & 615,310 & $3,666,147$ & 43 \\
P25 & $1,766,910$ & 103,497 & $1,167,958$ & 27 \\
P75 & $16,370,799$ & $2,718,327$ & $11,676,456$ & 86 \\
N & $5,324,814$ & $5,324,814$ & $5,324,814$ & $4,821,870$ \\
\hline
\end{tabular}

Notes: Authors' calculations based on data from Orbis. All monetary variables are expressed in U.S. dollars of 2005. Turnover refers to operating revenue; Capital corresponds to tangible fixed assets; Employment is the number of employees and the variable Costs of goods sold is the direct cost attributable to the production of the goods sold in a company, which includes the cost of the materials used in creating the good along with the direct labor costs used to produce the good. For countries reporting separately material and labor costs, we add these two variables to construct a synthetic costs of goods sold. 
Figure 1: Average Global Markup

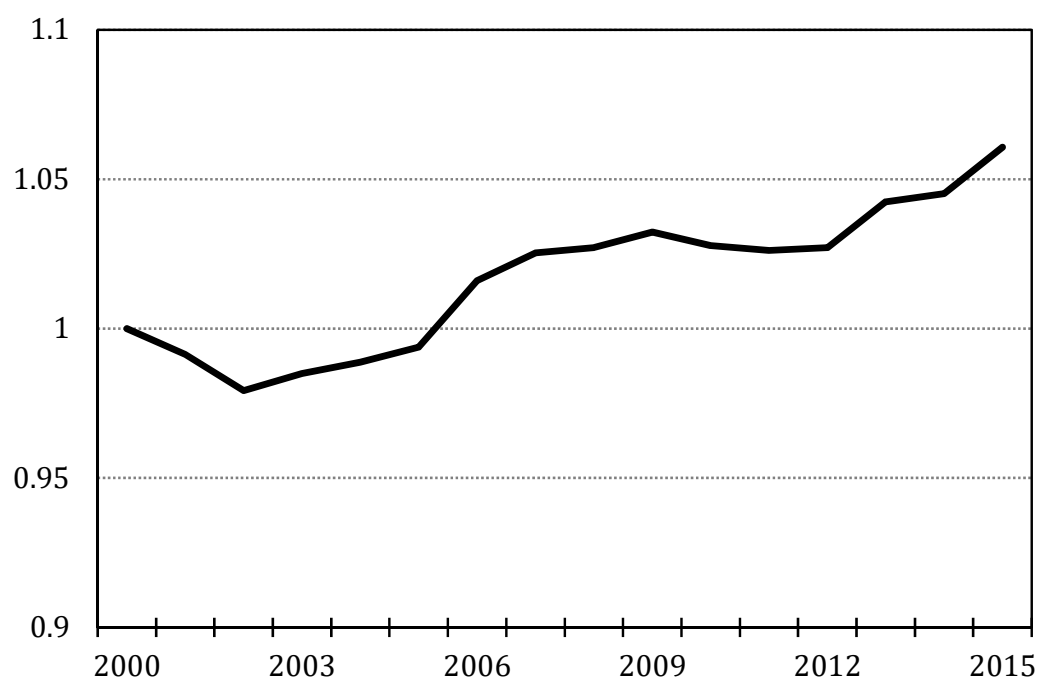

Notes: Authors' calculations based on data from Orbis. The sample includes all countries in the Baseline Sample of Table 1. Firm-level markups are estimated according to equation (6) where $\beta_{s}^{\nu}$ is estimated separately for each country-2-digit sector. Markups weighted by firm's revenue.

2000-2015. ${ }^{21}$ This corresponds to stylized fact (F1).

This increase, while significant (on average, over $1 / 3$ percentage points per year) is much more moderate than the one found by De Loecker and Eeckhout (2017, 2018) and Díez et al. (2018), even when considering the latter part of their samples that overlaps with our sample's time span. ${ }^{22}$ To reconcile these findings we need to consider the main difference between studies, namely, the fact that we include private firms in our sample while these earlier papers only cover publicly listed firms. ${ }^{23}$

\footnotetext{
${ }^{21}$ In Section 5 we document that the baseline results are robust to alternative estimation techniques (i.e., the estimation of a translog production function and a gross output production function following Gandhi et al. (2017)), concerns about changing technology (by re-estimating the production function over 5-year rolling windows) and finally, we stress the importance of the choice of input used in the markup calculation (i.e., the more flexible the input is, the more precise the markup estimate). Moreover, in Figure B.2 in Appendix B we show that firm profitability has also increased during this period, providing further evidence that the increase in markups corresponds to an increase in market power.

${ }^{22}$ Our findings are, however, in line with those by Calligaris et al. (2018) which are also based on Orbis. A recent additional paper that incorporates private firms to the analysis is that of De Loecker et al. (2018) who extend the analysis of listed firms in De Loecker and Eeckhout (2018) to incorporate U.S. Census information.

${ }^{23}$ The other main difference is the composition of countries in each sample. We look into the geographical component in the next section.
} 
Figure 2: High-markup, Middle, and Laggard Firms

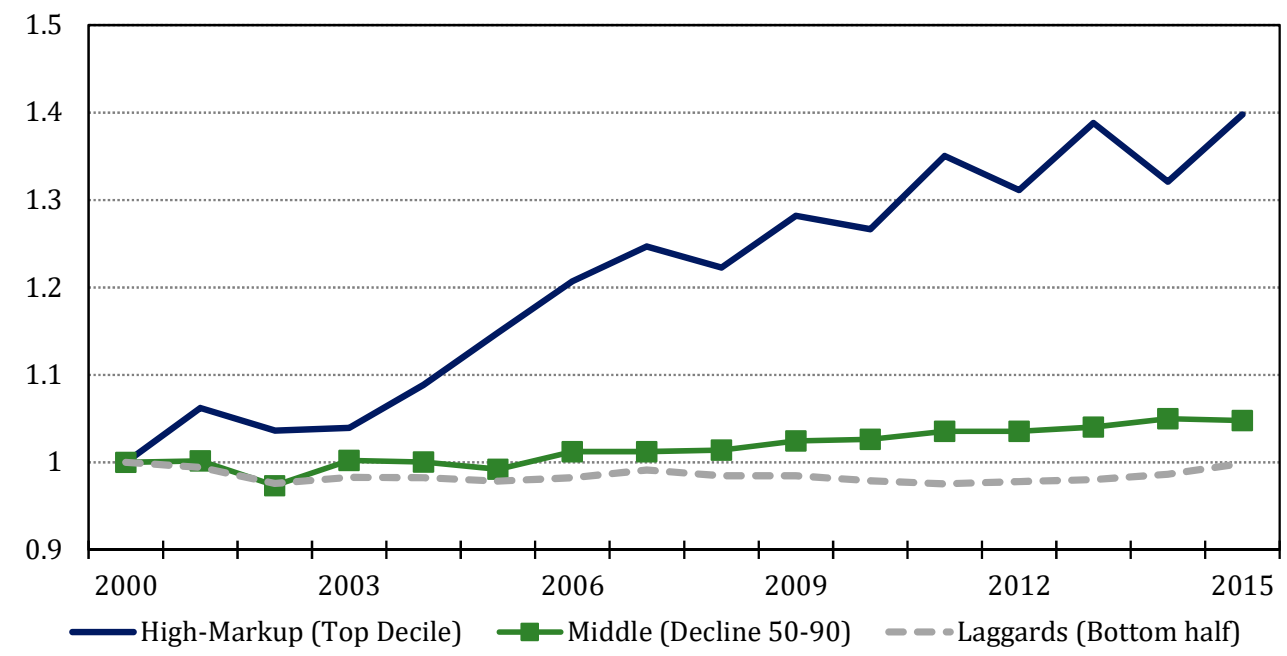

Notes: Authors' calculations based on data from Orbis. The sample includes all countries in the Baseline Sample of table 1. Firm markups are estimated according to equation (6) where $\beta_{s}^{\nu}$ is estimated separately for each sector. Markups weighted by firms' revenue. High-markup firms are defined as those firms in the upper decile of the markup distribution; middle firms as those between the median and the 90th percentile; laggard firms are defined as those in the bottom decile of the distribution.

\subsection{High-markup Firms}

The documented 6 percent increase in markups can be actually misleading because it conceals substantial heterogeneity. Indeed, the average increase results from the coexistence of three groups of firms that stand out when analyzing the distribution of markups. Specifically, we sort firms into three groups: the high-markup firms correspond to the upper decile of the markup distribution, the firms in the middle group correspond to those located between the median and the 90th percentile, and the laggard firms are those below the median. ${ }^{24}$

Figure 2 plots the evolution of markups for the firms in each group. The differences between groups are stark: while the high-markup firms increased their markups by 40 percent, the laggard firms kept their markups unchanged and those in the middle of the distribution increased markups only slightly. This corresponds to stylized fact (F2).

The question naturally arises: who are these high-markup firms? Large firms come first to mind - however, this would be an incomplete picture. Indeed, the group of high-markup firms is

\footnotetext{
${ }^{24}$ The deciles to assign firms to the different groups were computed by calculating the average markup of each firm during the whole sample; thus, the deciles are time-invariant. It follows that high-markup firms do not only show higher rates of growth in markups but also by construction display higher average markup levels. The results are robust to recomputing the deciles every year.
} 
composed by some large (including publicly listed) firms but the majority of the firms within the group are actually rather small and privately held. While this may be counter-intuitive at first, it can be rationalized if one thinks of firms operating in niche markets as described by Holmes and Stevens (2014). It follows that the exclusion of private firms from the analysis would affect the entire distribution of markups and not just one tail. In section 6 we analyze in detail the relationship between firm size and markups.

High-markup firms are found in all broad economic sectors, see Table 3. This implies that there is substantial heterogeneity in markups within sectors. The dispersion in markups is not limited to broadly defined sectors - in a similar fashion as Syverson (2011), who finds large productivity differences within narrowly defined sectors, we also find significant differences in firm markups within four-digit industries that importantly, have been increasing over time (see Figure B.3 in Appendix B).At the same time, firms in sectors such as information and communication, wholesale and retail, or accommodation and food services are relatively more likely to be high-markup firms. In terms of revenue, the most important sectors in this group are manufacturing, utilities, information and communication, and the financial sector.

\section{$5 \quad$ Extensions and Robustness Analysis}

\subsection{Digital Economy}

The previous section showed that the global increase in markups is driven by the high-markup firms in the top decile and that these firms are found in all broad economic sectors. At the same time, there is evidence that those sectors from the so-called digital economy have gained market power in recent years; see Calligaris et al. (2018). In light of this, we look at the sectoral decomposition of the markups' dynamics and, in particular, we zoom into the dynamics of those sectors that use more intensively the information and telecommunication technologies (ICT).

We identify those sectors that are ICT intensive users by constructing a measure based on OECD (2017) estimates for the digital economy. Specifically, each broad economic sector is sorted into quartiles depending on its ICT usage along several dimensions: software investment, ICT tangible investment, intermediate ICT goods, intermediate ICT services and robot use. We then 
Table 3: High-markup firms by Sector

\begin{tabular}{lcc} 
& Share of Firms & Share of Sales \\
\hline Agriculture, forestry and fishing & $1 \%$ & $0 \%$ \\
Mining and quarrying & $2 \%$ & $6 \%$ \\
Manufacturing & $6 \%$ & $16 \%$ \\
Electricity, gas, steam and AC & $1 \%$ & $17 \%$ \\
Water supply; sewerage; waste management & $3 \%$ & $1 \%$ \\
Construction & $6 \%$ & $1 \%$ \\
Wholesale and retail trade & $15 \%$ & $5 \%$ \\
Transporting and storage & $8 \%$ & $8 \%$ \\
Accommodation and food service & $11 \%$ & $9 \%$ \\
Information and communication & $10 \%$ & $11 \%$ \\
Financial and insurance activities & $6 \%$ & $10 \%$ \\
Real estate activities & $7 \%$ & $2 \%$ \\
Professional, scientific and technical serv. & $8 \%$ & $3 \%$ \\
Administrative and support services & $6 \%$ & $2 \%$ \\
Education & $1 \%$ & $0 \%$ \\
Human health and social work activities & $4 \%$ & $4 \%$ \\
Arts, entertainment and recreation & $3 \%$ & $2 \%$ \\
Other services activities & $2 \%$ & $3 \%$ \\
\hline
\end{tabular}

Notes: Authors' calculations based on data from Orbis. High-markup firms are defined as those firms in the upper decile of the markup distribution. Column (1) reports the share number of high-markup firms in a sector as share of the total number high-markup firms. Column (2) reports the average revenue of the high-markup firms within a sector as share of total average revenue of the decile.

define a sector as ICT intensive if it is above the median in at least four of these categories. Figure 3 presents the evolution of markups for the ICT-intensive sectors versus the average. The former indeed present higher-than-average increases in their market power, with average markups increasing twice as much as the overall aggregate - these findings are in line with Calligaris et al. (2018).

\subsection{Alternative Panel and Geographical Disparities}

In our baseline sample, we have data for 20 countries spanning over the 2000-2015 period. We also consider an alternative panel that, due to limitations in the time series for some countries, is shorter but wider, covering 28 countries over 2004-2013 - see Table 1 for the list of countries included. Compared to our baseline panel, this alternative data set includes some very large 
Figure 3: Average Markups, ICT-Intensive vs All firms

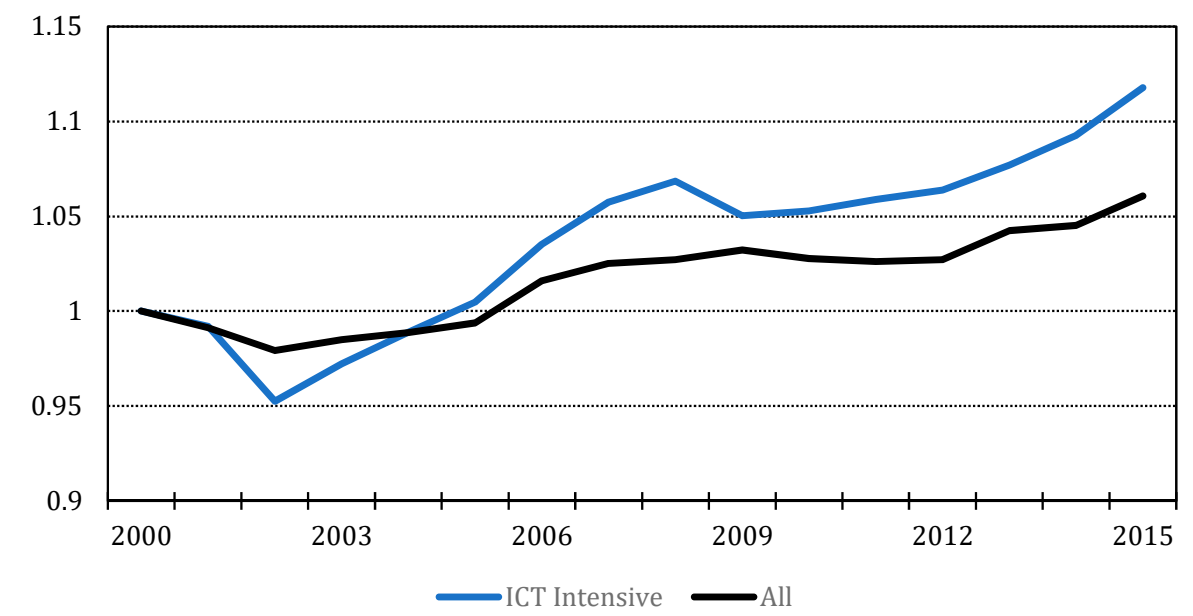

Notes: Authors' calculations based on data from Orbis; ICT intensity computed based on data from the OECD.

countries like China and Germany that were not included before. While the time series is shorter, this alternative panel has a better representation of the world economy.

Therefore, with this alternative sample we can take a look at the geographical differences in the evolution of markups. In Figure 4 we plot the markups for the advanced economies and for the emerging markets in the sample. The differences are stark and is clear that the global increase in markups is driven by the advanced economies, whose markups increased by almost 5 percent during 2004-2013. This is in sharp contrast with the markups for the emerging markets, which remain essentially unchanged during the period considered. This corresponds to stylized fact (F3). It is worth noting that these findings are in line with Díez et al. (2018) and De Loecker and Eeckhout (2018), who also document increases among advanced economies and mostly stagnant markups among emerging markets, albeit using data for publicly traded firms only.

\subsection{Alternative Specification and Methodology}

The baseline aggregate results might be subject to methodological concerns. In this subsection we address potential caveats and show results in Figure 5. 
Figure 4: Advanced Economies vs Emerging Markets

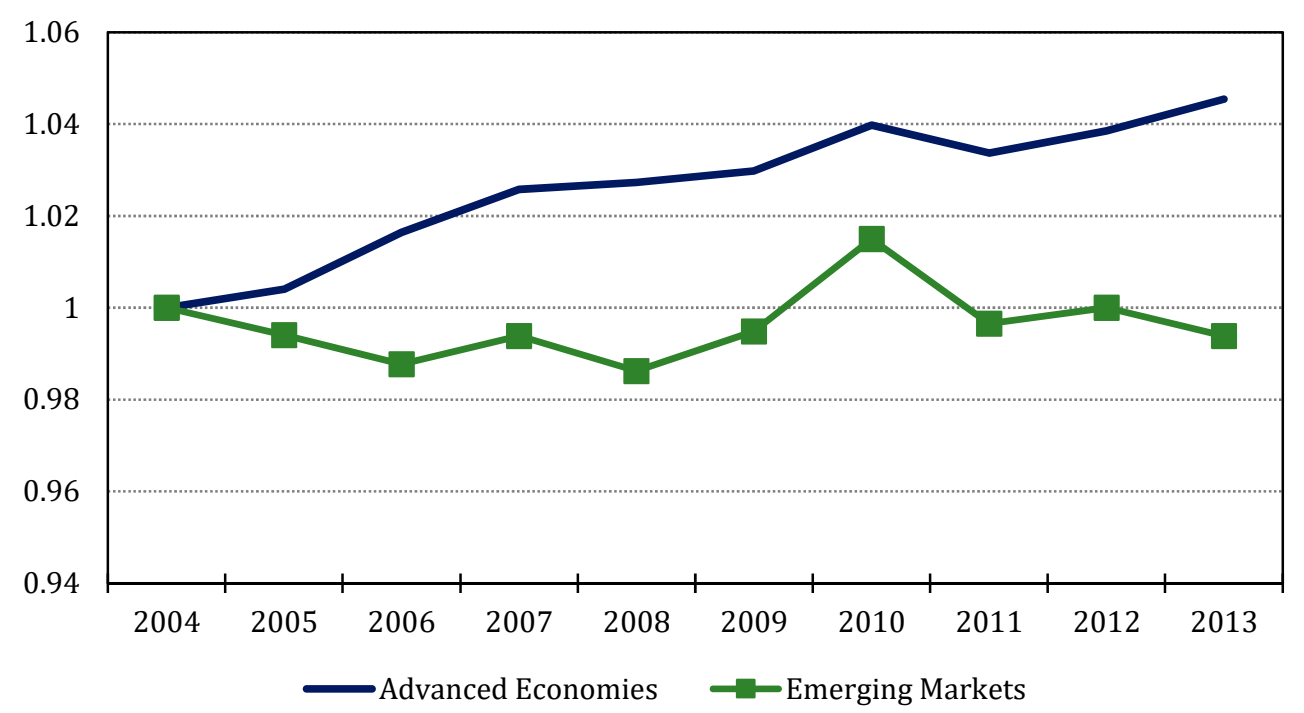

Notes: Authors' calculations based on data from Orbis. Firm markups are estimated according to equation (6) where $\beta_{s}^{\nu}$ is estimated separately for each country-2-digit sector. Markups weighted by firm revenue. See Table 1 for the list of countries.

\subsubsection{Rolling Window}

A plausible concern is that we are implicitly assuming that technologies are constant throughout the period considered. From equation (6) used for the markup calculation, it is clear that if the $\beta$ is fixed over time so is the technology. ${ }^{25}$ This could bias markup trends because changes in expenditure shares translate one to one into markup changes creating an artificial wedge when the production function elasticities are not correctly estimated.

To address this concern, we conduct a rolling window estimation. That is, we estimate the production function for 5-year periods and then impute to any given year $t$ the average estimated $\beta$ 's for all years in which $t$ was used for estimation. In this way, we introduce additional flexibility into the estimation by having time-varying $\beta$ 's. Panel A in Figure 5 shows that the markups from the rolling window estimation are fairly similar to those from the baseline estimation. This suggests that, regardless of the assumptions on the variability of technology, we still observe a moderate markup increase in global markets throughout the 2000s.

\footnotetext{
${ }^{25}$ The critique is only valid for the Cobb-Douglas estimation but not for the translog production function considered above since the translog elasticities are firm specific and vary over time (although the underlying parameters are still constant).
} 


\subsubsection{Overhead Costs}

Another potential concern is that our baseline markup estimates may be driven by a change in the production technology towards greater fixed (overhead) costs and lower marginal costs. This would imply that the increase in markups reflects firms recouping their original down payments, rather than an increase in market power. To address this concern, we re-estimate our production function, explicitly incorporating overhead costs as an additional input. ${ }^{26}$

We re-compute markups using the new estimates for the output elasticity of the costs of good sold that control for the effects of overhead costs. We present the results in Panel B of Figure 5, where we observe that the increase (not the level) of the average markups remains mostly unchanged by this adjustment. ${ }^{27}$ We conclude that technological change associated with shifts in overhead costs plays a small part in the overall rise in markups. ${ }^{28}$

\subsubsection{Production Function Estimation}

Another possible critique is that the results might be driven by technical choices such as the Cobb-Douglas production function specification or the underlying methodology used to estimate the input elasticity (and the TFP). To address these concerns we re-estimate the average global markup using a translog production function.

In addition, Gandhi et al. (2017) highlight concerns about the traditional (control function) approach to estimate production functions. Specifically, they argue that there is no proper identification if the flexible input in the production function is also used as the proxy variable in the control function - which expresses demand for flexible inputs as a function of unobserved productivity and the capital stock. ${ }^{29}$ To overcome the critique, we follow their approach and estimate

\footnotetext{
${ }^{26}$ In Orbis, this corresponds to the variable "Other Operating Expenses" that include for example, sales and marketing expenses, plus administrative expenses and other operating expenses. The number of observations reporting "Other Operating Expenses" corresponds to roughly half of the sample and, therefore, the results we report below (Figure 5, Panel B) use this subsample to compute the corresponding baseline case.

${ }^{27}$ The production function estimation that includes overhead costs results in estimated elasticities that are consistent with constant returns to scale - the elasticities add up to 0.995. In the case of the baseline estimation of the production function, returns to scale are between 0.92 and 0.93 , consistent with most of the literature. In both cases, estimates are stable over time.

${ }^{28}$ See De Loecker and Eeckhout (2018), Karabarbounis and Neiman (2018), Traina (2018), and Díez et al. (2018) for a similar approach using data on publicly listed firms. Díez et al. (2018) also show that, while the markup level is affected, the evolution of markups is not affected by the inclusion of overhead costs in the production function.

${ }^{29}$ This is even more troublesome if the elasticity with respect to this input is precisely the one used for the markup estimation (as is the case with COGS).
} 
in the first step the coefficient on the flexible input by estimating the inverse share equation - a transformation of the firm's first order condition - and, in the second step estimate the coefficient on capital.

The resulting markups from the translog production function and from the Gandhi et al. (2017) estimation approach are highly correlated with our baseline results. If we use a translog the resulting increase in markups over the 2000-2015 period amounts to 10 percent, whereas the resulting increase is of 2 percent if we use Gandhi et al. (2017) approach. Thus, our baseline estimates are right in between both alternatives, all pointing towards a moderate increase in the global average markup since 2000 (see panel C in Figure 5).

\subsubsection{Choice of Flexible Input}

In our baseline estimations we regress a production function with a composite variable input, namely, cost of goods sold (COGS). This input is essentially composed of the operations costs associated to labor and materials and, for roughly half of our countries, this is all we observe. However, for several European countries we observe labor and materials costs separately - that is, we are able to look into the composition of COGS. ${ }^{30}$ While the expenditure on materials can be thought of as close to being fully flexible, the labor costs can actually be quite rigid, especially in some European countries whose labor markets are heavily regulated. Since the identification of the markups through the producer's costs minimization problem relies on the input being really flexible, this analysis can be particularly relevant for these countries.

In Panel D of Figure 5 we plot the evolution of markups for these European countries, considering both alternative inputs, COGS and materials. The results highlight how different inputs can deliver different messages: the markups computed using materials increased by around 6 percent while those using COGS by around 3 percent. ${ }^{31}$ Taken at face value, this implies that our baseline estimates are rather conservative and can be thought of as a lower bound.

\footnotetext{
${ }^{30}$ These countries are: Belgium, Bulgaria, Estonia, Finland, France, Hungary, Italy, Poland, Portugal, Romania, Slovenia, and Spain.

${ }^{31}$ The figure shows the results using the method by Gandhi et al. (2017) but the same pattern is observed when using the approach by De Loecker and Eeckhout (2017).
} 
Figure 5: Markups: Robustness Analysis

\section{A. Rolling Window}

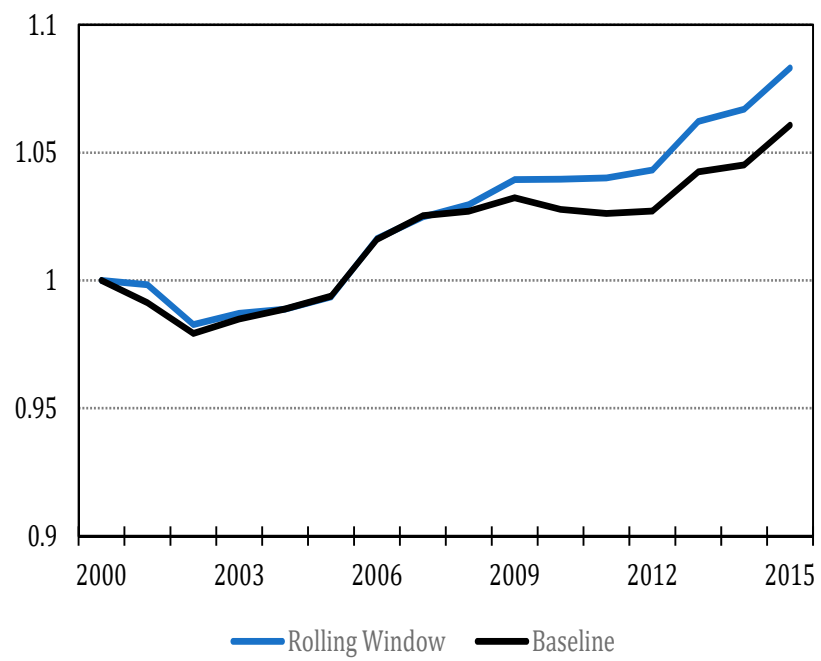

C. Translog and GNR

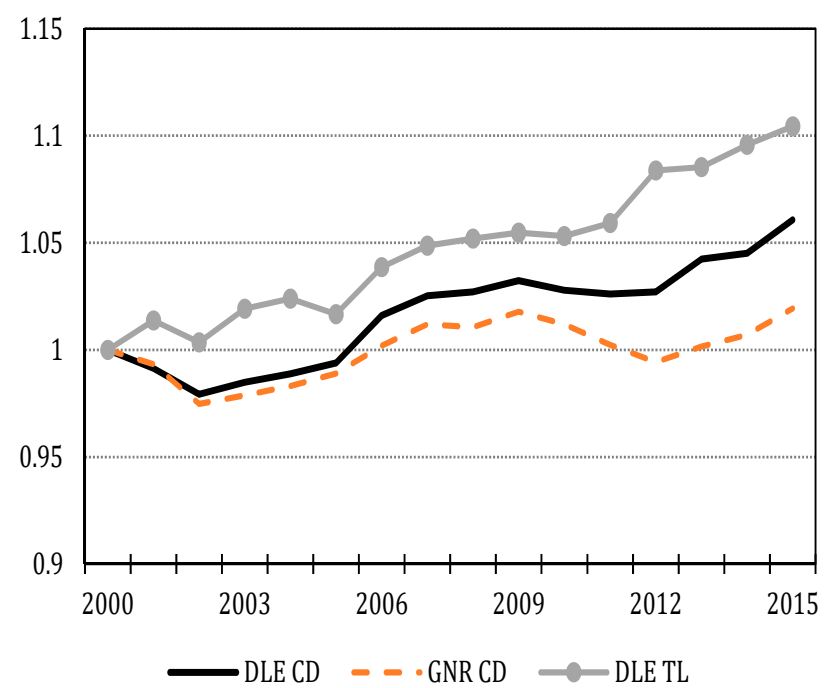

B. Overhead Costs

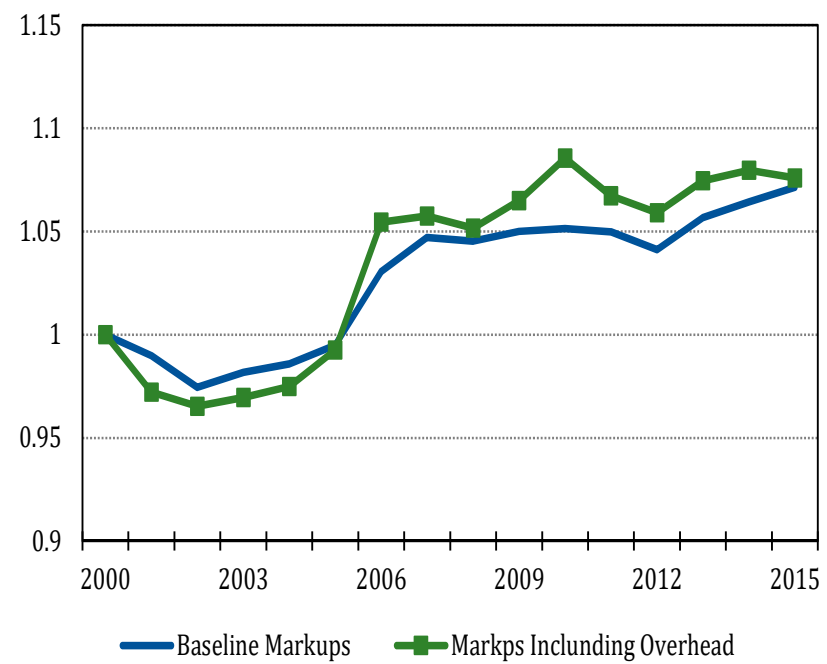

D. COGS vs Materials

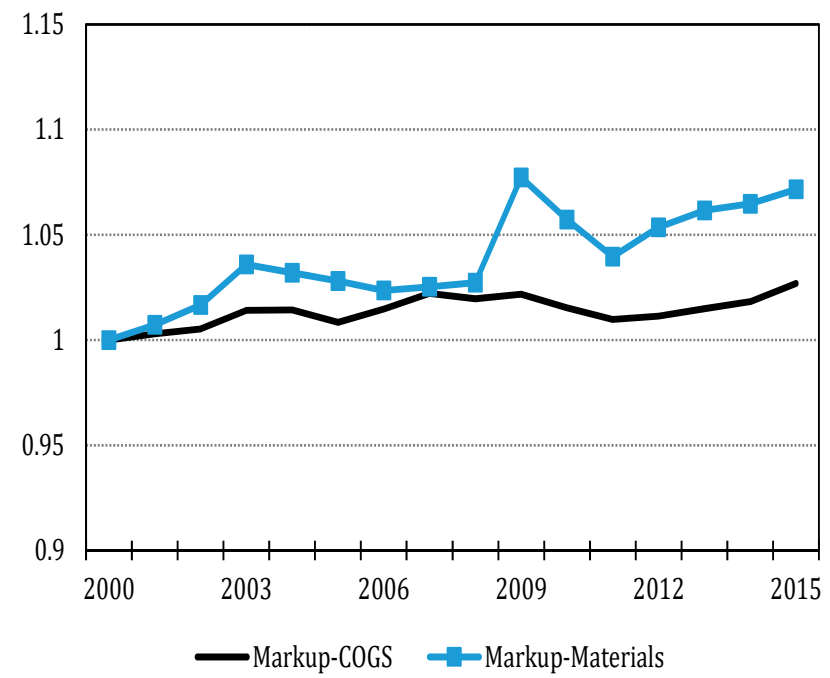

Notes: Authors' calculations based on data from Orbis. The sample of countries are those in the Baseline Sample of table 1. Markups weighted by firm revenues. Firm markups are estimated according to equation (6). The production function is estimated separately for each sector. In Panel A: we estimate a Cobb-Douglas production function for 5-year periods and then impute to any given year $t$ the average estimated $\beta$ for all years in which $t$ was used for estimation. Panel $\boldsymbol{B}$ estimates a CobbDouglas production function adding overhead costs as an additional input; markups are obtained using cost of goods sold. In Panel $\boldsymbol{C}$ : DLE CD $\beta_{s}^{\nu}$ is based on a Cobb-Douglas production function. DLE TL refers to a translog production function. GNR CD follows Gandhi et al. (2017) and estimate a gross output Cobb-Douglas production function. Panel $\boldsymbol{D}$ follows a GNR CD estimation, where $-M A T$ recovers the firm markup from the elasticity of the materials input and -COGS recovers the firm markup from the cost of goods sold. 
Figure 6: Markup and Firm Size: Unconditional Correlation

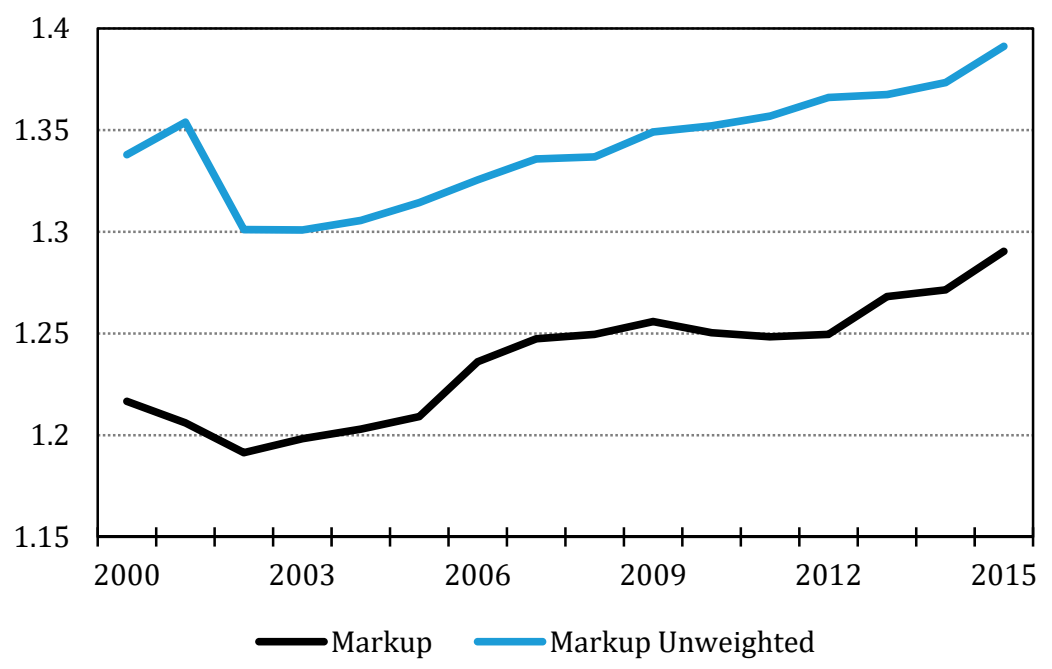

Notes: Authors' calculations based on data from Orbis. The black line shows the level of the weighted average markup during the period (markups weighted by firms' revenue). The blue line reports the unweighted average markup.

\section{Markups and Size}

In this section we explore the relation between firm markups and size. As shown in Figure 2, high-markup firms are the ones driving the increase in markups during the period of analysis. However, Figure 6 shows that the unweighted average markup is above the weighted average markup, suggesting that larger firms, defined as those with higher sales, have lower markups. De Loecker and Eeckhout (2017) find a negative correlation between markups and size that becomes positive when looking within narrowly defined industries. We conduct the same cross-sectional decomposition and find a negative relation, even within narrow industries - it is only when we look at the top 5 percentile of the distribution of firm real sales that we find a positive relation. To shed some light on these a priori contradictory results we next turn to explore the relationship between firm markups and size in detail.

\subsection{Cross-Sectional Decomposition}

We follow De Loecker and Eeckhout (2017) and use the following decomposition proposed by Olley and Pakes (1996):

$$
\mu_{t}=\sum_{i} s_{i t} \mu_{i t}=\bar{\mu}_{t}+\sum_{i}\left(s_{i t}-\bar{s}_{t}\right)\left(\mu_{i t}-\bar{\mu}_{t}\right)
$$


where $\mu_{t}$ is the firm-sales-weighted average markup; $s_{i t}$ is the share of firm $i$ 's sales $\left(P_{i t} Y_{i t}\right)$ in total

sales in the economy $\left(S_{t}=\sum_{i, t} P_{i t} Y_{i t}\right) ; \bar{\mu}_{t}$ is the unweighted average of markups and the second term shows the covariance between firm size $\left(s_{i t}\right)$ and firm markup $\left(\mu_{i t}\right)$.

In Figure $6, \mu_{t}$ is the black solid line, $\overline{\mu_{t}}$ is the blue line, and the difference between the two is the last term in equation (7) representing the covariance between the firm size and markup. The fact that the weighted average is always below the unweighted average implies that larger firms have lower markups. This covariance term has slightly increased since the global financial crisis. De Loecker and Eeckhout (2017) find a similar result and argue that although the previous result holds across all firms and all sectors, within narrowly defined industries there is instead a positive relationship between markups and size. To show this last point they implement the following decomposition:

$$
\mu_{t}=\bar{M}_{t}+\sum_{s}\left(s_{s t}-\overline{s_{s t}}\right)\left(\mu_{s t}-\bar{M}_{t}\right)
$$

where $\bar{M}_{t}=\frac{\sum_{s} \mu_{s t}}{S_{t}}$ is the unweighted sectoral average (we use the four-digit industry sectoral classification) and $S_{t}$ represents total sales.

In Figure 7 we present our findings after conducting this same decomposition. The black line in Panel A shows the average weighted markup $\left(\mu_{t}\right)$ while the orange line shows $\bar{M}_{t}$. The figure shows the negative correlation holds even within narrowly defined industries, although the negative covariance has been decreasing over time, especially in recent years. Panel B in Figure 7 shows that the within sector correlation is only positive for the top 5 percentile of the distribution of firm sales, in line with the results shown in De Loecker and Eeckhout (2017) using data for publicly listed U.S. firms. It follows that markups and firm size are (unconditionally) negatively correlated except at the very top of the size distribution. Next, we further explore this relation to shed some extra light and reconcile our findings.

\subsection{A U-Shaped Relationship}

In this section we show that the relationship between markup and size is non-monotonic. We begin by plotting the share of average sales by the firms in each decile of the markup distribution. This is reported in Figure 8, where is apparent that, while markup and size are negatively related overall, there is a positive relationship when focusing o the three upper deciles. Thus, there seems 
Figure 7: Markup and Firm Size: Sectoral Decomposition

A. All Firms

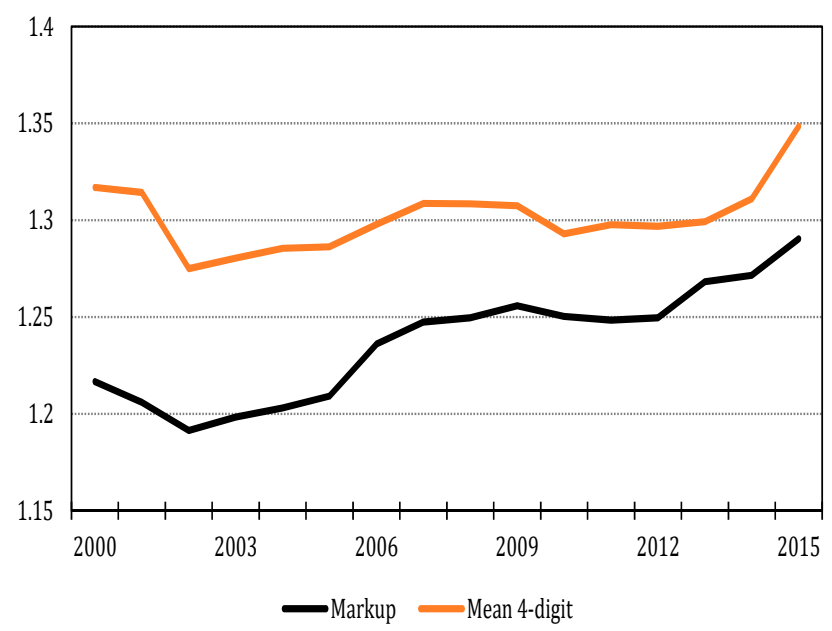

B. Top 5 percentile

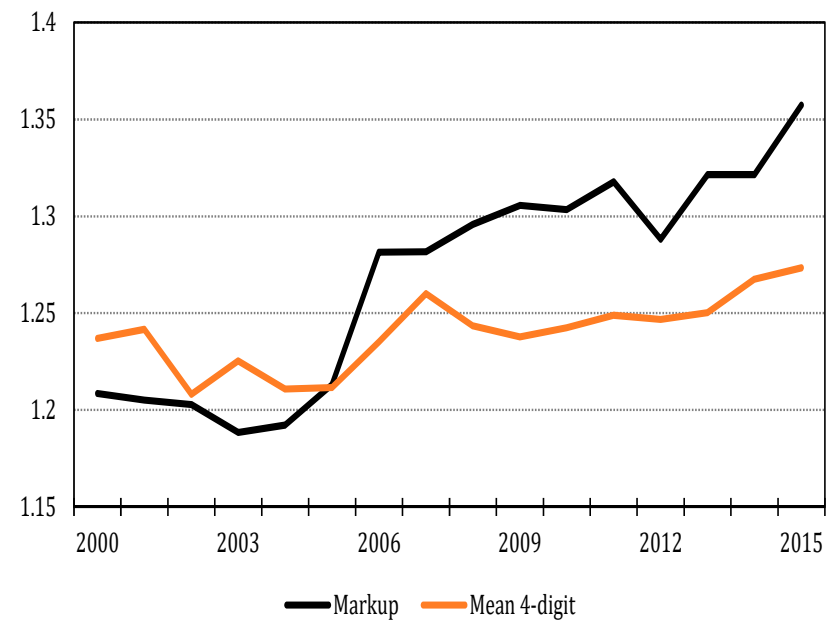

Notes: Authors' calculations based on data from Orbis. In Panel A the black line reports the weighted average markup (markups weighted by firms' revenue) and the orange line reports the unweighted sectoral average (four-digit industry sectoral classification). Panel B repeats the analysis for the top 5 percentile of the firm sales distribution. The black line reports the unweighted average markup while the orange line reports the unweighted sectoral average.

to be an (unconditional) non-monotonicity.

Figure 8: Share of Revenue per Decile

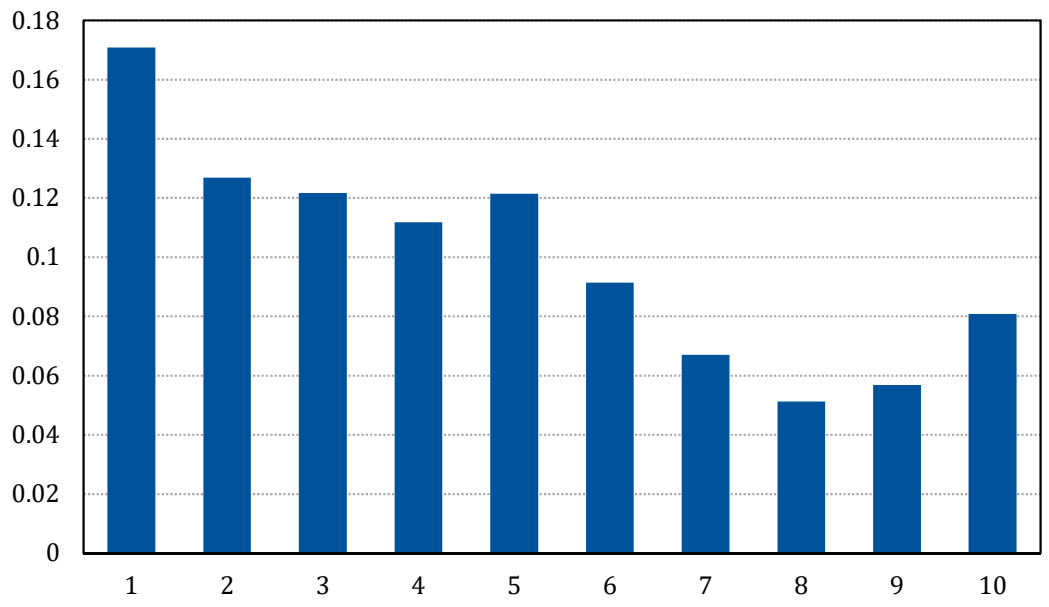

Notes: Authors' calculations based on data from Orbis. Each bar (representing a decile of the markup distribution) plots the share of total average revenue of the decile in total average revenue.

We next look at the relationship between markups and size conditioning on firm observable characteristics. Specifically, Table 4 shows the correlation between firm markups and size (mea- 
sured by market share, computed as the share of firm output in total country-four-digit industryyear output) conditioning on country-four-digit industry-year fixed effects. ${ }^{32}$ Columns (1) to (3) show the cross sectional results while columns (4) to (6) show the within-firm results, that is, when firm fixed effects are included.

Column (1) reinforces the unconditional results commented in the previous section: larger firms charge, on average, lower markups. However, in column (2) we find that the relationship is not linear. The positive coefficient on the quadratic term suggests that the relation between markup and size is first negative and eventually becomes positive. The total effect varies by firm size and only becomes positive for firms around the 95th percentile of the market share distribution. This corresponds to stylized fact $(\mathbf{F} 4)$. The remaining columns in Table 4 show that the results are robust to controlling for differences in productivity and overhead costs across firms (column (3)) and that similar effects are found when including firm fixed effects (columns (4)-(6)).

Table 4: Markups and Firm Size: Conditional Correlation

Dependent Variable: log Firm Markup

\begin{tabular}{|c|c|c|c|c|c|c|}
\hline & $(1)$ & $(2)$ & $(3)$ & (4) & (5) & $(6)$ \\
\hline & \multicolumn{3}{|c|}{ Cross-Section } & \multicolumn{3}{|c|}{ WiThIN FIRM } \\
\hline$M S$ & $-0.396^{* * *}$ & $-1.277^{* * *}$ & $-1.476^{* * *}$ & $-0.472^{* * *}$ & $-1.443^{* * *}$ & $-1.267 * * *$ \\
\hline$M S^{2}$ & & $1.346^{* * *}$ & $1.534^{* * *}$ & & $1.295^{* * *}$ & $1.135^{* * *}$ \\
\hline $\log T F P$ & & $(0.015)$ & $\begin{array}{c}(0.024) \\
0.744 * * *\end{array}$ & & $(0.016)$ & $\begin{array}{c}(0.022) \\
0.557 * *\end{array}$ \\
\hline & & & $(0.006)$ & & & $(0.006)$ \\
\hline $\log$ Overhead & & & $\begin{array}{c}-0.029 * * * \\
(0.000)\end{array}$ & & & $\begin{array}{c}-0.030^{* * *} \\
(0.000)\end{array}$ \\
\hline Observations & $5,303,984$ & $5,303,984$ & $2,394,304$ & $5,201,324$ & $5,201,324$ & $2,296,207$ \\
\hline Firm FE & no & no & no & yes & yes & yes \\
\hline Country-Ind-Year FE & yes & yes & yes & yes & yes & yes \\
\hline Cluster & id & id & id & id & id & id \\
\hline
\end{tabular}

Notes: The dependent variable is the log of firm markup recovered for the estimation of a Cobb-Douglas production function and using the cost of goods sold as the flexible input. $M S$ refers to the market share measured as the share of firm sales in total country-sector-4-digit-year sales. $\log T F P$ stands for the log of total factor productivity. $\log$ Overhead stands for the log of other operating expenses. Columns (1) to (3) do not include firm fixed effects. Columns (4) to (6) include firm fixed effects. Standard errors are clustered at the firm level are reported in parentheses.

\footnotetext{
${ }^{32}$ Similar results are found if revenue or employment are used as a measure of firm size (see table B.1 in Appendix B). Furthermore, the findings are robust to having one period lagged values of the regressors.
} 


\subsection{Dynamic Decomposition with Firm Entry and Exit}

Finally, we explore the (relative) importance of different factors in explaining the overall markup increase. Specifically, we follow Melitz and Polanec (2015) to decompose the increase in average firm markups over time into the contribution by incumbent, entering and exiting firms. In addition, we decompose the effect of each type of firm into a "within component" (i.e., how much of the markup increase is driven by increases in average firm markups) and a "reallocation component" (i.e., how much of the markup increase is driven by larger firms increasing their market shares). ${ }^{33}$

We look at the period 2000-2015 and define incumbent firms as those that were present both in 2000 and in 2015. Entering firms are those that were not in the sample in 2000 and by 2015 report at most 15 years of age - therefore, these are firms that enter the economy at some point between 2001 and 2015. Finally, exiting firms are those that were present in 2000 but did not report any financial information between 2001 and 2015. The average markup increase in this sample of firms between 2000 and 2015 is $6.4 \%{ }^{34}$

Table 5 reports the decomposition results: $70 \%$ of the markup increase between 2000 and 2015 is explained by markup increases by incumbent firms. In terms of the extensive margin, entering firms positively contribute to the markup growth during the period explaining $42 \%$ of the observed increase, while the contribution of exiting firms is more limited and brings the markup growth rate down. The breakdown by within-firm and reallocation effects presents some interesting differences. First, in the case of incumbent firms, shifts in the distribution of firm markups (the unweighted mean change in the markup of incumbent firms between 2000 and 2015) explain most of the increase in average markups for incumbent firms. However, there is a negative reallocation effect (measured as the change in the covariance between firm markup and market share in 2000 and 2015) that brings the markup increase down and suggests that over time, within the sample of incumbent firms, the covariance between firm markup and market share has decreased. Second, entering firms also significantly contribute to the observed markup increase during the period.

\footnotetext{
${ }^{33}$ Appendix C shows the details of the Melitz and Polanec (2015) decomposition in levels.

${ }^{34}$ Notice the precise definition of incumbent, entering and exiting firms to avoid concerns related to the misclassification of firms based on entering and exiting into the sample rather than the population, leaves out of the current sample two types of firms that are present in our baseline results. First, we exclude firms that were not present in 2000 but appear in 2015 and report age greater than 15 years. Second, we exclude firms that were present in 2000, do not report financial information in 2015 but however, report some financial information at some point between 2001 and 2014. Changing the definition of exit (for example to those that did not report financial information between 2010-2015) increases the role of exit but does not change our main results for incumbent and entrant firms.
} 
Interestingly, in this case the relative importance of distribution shifts and reallocation effects is reversed. The first row shows that the unweighted average markups of entrants in 2015 is close to $1 \%$ lower than the corresponding average of incumbent firms in 2015. Therefore, entrants on average do not set higher markups than incumbent firms. However, there is a significant increase in the reallocation term. This is the difference between the covariance of markup and market share of entrants and the corresponding covariance of incumbent firms. Entrants with high markups have higher market shares compared to incumbent firms. Finally, exitors contribute negatively to the markup increase between 2000 and 2015. This result is mainly driven by differences in the average markup so that the average markup of exiting firms is higher than the average markup of incumbent firms in 2000. To summarize, the markup increase between 2000 and 2015 can be mainly explained by increases in the average markup of incumbent firms and by sizable reallocation effects towards new firms that gain market share during the period compared to incumbent firms. This corresponds to stylized fact (F5).

Next, we focus once again on the set large firms to examine whether we observe a differential pattern in this case as well. In panel $\mathrm{B}$ of Table 5 we report the corresponding decomposition for the sample of large firms (the top 5 percentile of the sales distribution). In this sub-sample, we find that now the within-firm average markup and the reallocation effects contribute equally to the observed increase in incumbent firms' average markup. Further, in the case of entrants, the increase in average markups is purely driven by reallocation effects. Therefore, in the case of large firms, the reallocation effects both from continuing firms and new entrants can explain $60 \%$ of the average markup increase between 2000 and 2015. Furthermore, it should be noted that this pattern is even strengthened if we conduct the decomposition only for U.S. firms, that has a significant fraction of the largest firms in the world. In this case, we find an overall increase almost twice as large as the average $(11.5 \%)$ but where the reallocation of resources towards highmarkup firms account for almost $80 \%$ of the total increase. These findings are consistent with Baqaee and Farhi (2017), that using data on U.S. listed companies, find evidence consistent with resources being allocated towards high-markup firms. ${ }^{35}$ Thus, the data suggest that a significant difference between the U.S. firms and the rest of our sample (mainly European firms) has been a large reallocation of resources away from low-markup, low-productivity firms toward high-markup,

\footnotetext{
${ }^{35}$ We thank Farhi for his insights on this topic.
} 
high-productivity firms. This between component can be growth-enhancing if high-markup firms are also more productive at the margin.

Table 5: Dynamic Firm Markup Decomposition 2000-2015

\begin{tabular}{|c|c|c|c|c|c|}
\hline \multicolumn{6}{|c|}{ Panel A: Baseline Sample } \\
\hline & $\Delta \mu$ & Incumbent Firms & Entering Firms & Exiting Firms & TOTAL \\
\hline $\begin{array}{l}\text { Within Firm Growth } \\
\text { Market Share Reallocation }\end{array}$ & 0.064 & $\begin{array}{r}0.045 \\
0.064 \\
-0.019\end{array}$ & $\begin{array}{c}0.027 \\
-0.009 \\
0.036\end{array}$ & $\begin{array}{c}-0.008 \\
-0.009 \\
0.002\end{array}$ & $\begin{array}{l}0.045 \\
0.019\end{array}$ \\
\hline \multicolumn{6}{|c|}{ PANel B: Top 5 Percentile of the SAles distribution } \\
\hline & $\Delta \mu$ & Incumbent Firms & Entering Firms & Exiting Firms & TOTAL \\
\hline $\begin{array}{l}\text { Within Firm Growth } \\
\text { Market Share Reallocation }\end{array}$ & 0.073 & $\begin{array}{l}0.056 \\
0.030 \\
0.026\end{array}$ & $\begin{array}{c}0.015 \\
-0.002 \\
0.017\end{array}$ & $\begin{array}{l}0.002 \\
0.001 \\
0.001\end{array}$ & $\begin{array}{l}0.028 \\
0.045\end{array}$ \\
\hline
\end{tabular}

Notes: The table reports the change in markup between 2000 and 2015 and the corresponding decomposition. Incumbent firms are those that were present in 2000 and in 2015. Entering firms are those that were not in the sample in 2000 and by 2015 report at most 15 years of age. Exiting firms are those that were present in 2000 but did not report any financial information between 2001 and 2015. For incumbent firms, within firm growth is the difference in the average markup of incumbent firms between 2000 and 2015. The market share reallocation is the difference between the covariance between firm markup and market share of incumbent firms in 2000 and 2015. For Entering firms, within firm growth is the difference in the average markup of entering firms minus the average markup of incumbent firms in 2015. The market share reallocation is the difference between the covariance of firm markup and market share of entering firms and the corresponding covariance for incumbent firms in 2015. For Exiting firms, within firm growth is the difference in the average markup of incumbent firms minus the average markup of exiting firms in 2000. The market share reallocation is the difference between the covariance of firm markup and market share of incumbent firms and the corresponding covariance for exiting firms in 2000. Panel A reports results for the Baseline Sample of firms and Panel B reports results for the top 5 percentile of the real sales distribution. 


\section{Conclusion}

In this paper we provide new evidence on the recent evolution of market power at the global level. Using detailed firm-level data from advanced and emerging countries we estimate markups and find a decrease in competition levels around the world. Specifically, we find that average markups increased by about 6 percent in 2000-2015.

However, there is sizable heterogeneity concealed in this average figure. Specifically, we show that the increase is driven by the high-markup firms at the top of the markup distribution, whose markups increased by 40 percent during the sample period. Further, we also find that the increases are prevalent mostly for firms from advanced economies.

Given the predominant role of high-markup firms we explore the relation between firm markup and size and present evidence of a non-monotonic (U-shaped) relationship. That is, we document that markups decrease with firm size until a (very large) size threshold is reached, after which we find a positive relation. In addition, we find that most of the increase in markups is explained by markup increases within incumbents and high markups among entrants. These findings could be relevant to understand competition in different markets and to think about appropriate policy responses to increases in markups. Inasmuch as higher markups are linked to firms' outcomes like investment, innovation, or the labor share, it is crucial for policymakers to understand the markups' recent dynamics as well as the significant sources of heterogeneity presented in the paper. 


\section{References}

Ackerberg, D. A., Caves, K., and Frazer, G. (2015). Identification Properties of Recent Production Function Estimators. Econometrica, 83(6):2411-2451.

Akcigit, U., Baslandze, S., and Lotti, F. (2018). Connecting to Power: Political Connections, Innovation, and Firm Dynamics. NBER Working Papers 25136, National Bureau of Economic Research, Inc.

Autor, D., Dorn, D., Katz, L. F., Patterson, C., and Reenen, J. V. (2017). The Fall of the Labor Share and the Rise of Superstar Firms. NBER Working Papers 23396, National Bureau of Economic Research, Inc.

Baqaee, D. R. and Farhi, E. (2017). Productivity and Misallocation in General Equilibrium. Working Paper No. 24007, National Bureau of Economic Research.

Barkai, S. (2017). Declining Labor and Capital Shares. LBS Working Paper.

Calligaris, S., Criscuolo, C., and Marcolin, L. (2018). Mark-ups in the Digital Era. OECD Science, Technology and Industry Working Papers, No. 2018/10.

Council of Economic Advisers (2016). Benefits of Competition and Indicators of Market Power. CEA Issue Brief April 2016.

De Loecker, J. and Eeckhout, J. (2017). The Rise of Market Power and the Macroeconomic Implications. Working Papers No. 23687, National Bureau of Economic Research.

De Loecker, J. and Eeckhout, J. (2018). Global Market Power. Working Paper No. 24768, National Bureau of Economic Research.

De Loecker, J., Eeckhout, J., and Unger, G. (2018). The Rise of Market Power and the Macroeconomic Implications. Technical report, mimeo.

De Loecker, J. and Warzynski, F. (2012). Markups and Firm-Level Export Status. American Economic Review, 102(6):2437-2471. 
Díez, F., Leigh, D., and Tambunlertchai, S. (2018). Global Market Power and its Macroeconomic Implications. IMF Working Paper No. 18/137.

Edmond, C., Midrigan, V., and Xu, D. Y. (2018). How Costly Are Markups? Working Paper No. 24800, National Bureau of Economic Research.

Eggertsson, G. B., Robbins, J. A., and Wold, E. G. (2018). Kaldor and Pikettys Facts: The Rise of Monopoly Power in the United States. Working Paper No. 24287, National Bureau of Economic Research.

Gal, P. N. (2013). Measuring Total Factor Productivity at the Firm Level using OECD-ORBIS. OECD Economics Department Working Papers 1049, OECD Publishing.

Gandhi, A., Navarro, S., and Rivers, D. (2017). On the Identification of Gross Output Production Functions. Forthcoming at Journal of Political Economy.

Gopinath, G., Kalemli-Özcan, S., Karabarbounis, L., and Villegas-Sanchez, C. (2017). Capital Allocation and Productivity in South Europe. The Quarterly Journal of Economics, 132(4):19151967.

Gutiérrez, G. and Philippon, T. (2017). Declining Competition and Investment in the U.S. Working Paper No. 23583, National Bureau of Economic Research.

Gutiérrez, G. and Philippon, T. (2018). How EU Markets Became More Competitive Than US Markets: A Study of Institutional Drift. NBER Working Papers 24700, National Bureau of Economic Research, Inc.

Hall, R. E. (1986). Market Structure and Macroeconomic Fluctuations. Brookings Papers on Economic Activity, 17(2):285-338.

Hall, R. E. (1988). The Relation between Price and Marginal Cost in U.S. Industry. Journal of Political Economy, 96(5):921-947.

Hall, R. E. (2018). New evidence on the markup of prices over marginal costs and the role of mega-firms in the us economy. Working Paper 24574, National Bureau of Economic Research. 
Holmes, T. J. and Stevens, J. J. (2014). An Alternative Theory of the Plant Size Distribution, with Geography and Intra- and International Trade. Journal of Political Economy, 122(2):369-421.

Inklaar, R. and Timmer, M. P. (2014). The Relative Price of Services. Review of Income and Wealth, 60(4):727-746.

Kalemli-Özcan, S., Sorensen, B., Villegas-Sanchez, C., Volosovych, V., and Yesiltas, S. (2015). How to Construct Nationally Representative Firm Level data from the ORBIS Global Database. Working Paper No. 21558, National Bureau of Economic Research.

Karabarbounis, L. and Neiman, B. (2018). Accounting for Factorless Income. In NBER Macroeconomics Annual 2018, volume 33, NBER Chapters. National Bureau of Economic Research, Inc.

Klette, T. J. (1999). Market Power, Scale Economies and Productivity: Estimates from a Panel of Establishment Data. Journal of Industrial Economics, 47(4):451-476.

Levinsohn, J. and Petrin, A. (2003). Estimating Production Functions Using Inputs to Control for Unobservables. The Review of Economic Studies, 70(2):317-341.

Melitz, M. J. and Polanec, S. (2015). Dynamic Olley-Pakes productivity decomposition with entry and exit. RAND Journal of Economics, 46(2):362-375.

OECD (2017). Taxonomy of sectors by quartile of digital intensity, 2013-15. Knowledge economies and the digital transformation, OECD Publishing, Paris.

Olley, G. S. and Pakes, A. (1996). The Dynamics of Productivity in the Telecommunications Equipment Industry. Econometrica, 64(6):1263-1297.

Syverson, C. (2011). What Determines Productivity? Journal of Economic Literature, 49(2):326365.

Syverson, C. (2018). Changing Market Structures and Implications for Monetary Policy. Remarks Made at the 2018 Jackson Hole Symposium.

Tirole, J. (1988). The Theory of Industrial Organization. MIT Press: Cambridge, MA. 
Traina, J. (2018). Is Aggregate Market Power Increasing? Production Trends Using Financial Statements. Technical report, SSRN.

Van Reenen, J. (2018). Increasing Differences Between Firms: Market Power and the MacroEconomy. CEP Discussion Papers dp1576, Centre for Economic Performance, LSE. 


\section{Appendix for Online Publication}

\section{A Data}

The Orbis dataset contains corporate balance sheet information retrieved from the Orbis Historical database, and other characteristics of firms, such as industry classification, date of incorporation, or legal status from the Current Orbis database. We followed the cleaning steps that are based on Kalemli-Özcan et al. (2015), Gopinath et al. (2017) and Gal (2013).

\section{A.1 Duplicates}

When there are duplicates found from data downloaded from Orbis, we adopt the following rules. (1) We kept company accounts that are unconsolidated (U1 or U2 in Orbis) or unknown (LF, stands for limited financials). (2) We removed accounts that are duplicates and not "annual report" types. (3) We removed accounts that are duplicates for firms reporting data that refers to less than 12 months of operations. (4) We kept accounts that are duplicates but have the closest reporting date to Dec. 31st in the corresponding year. (5) If there were still duplicates found, we kept those accounts that have more non-missing variables to calculate TFP.

\section{A.2 Data Cleaning}

We took two main steps to clean Orbis dataset including cleaning of basic reporting mistakes, and further quality checks on data consistency (see Kalemli-Özcan et al. (2015), Gopinath et al. (2017) and Gal (2013)).

- Cleaning of basic reporting mistakes

- We dropped firms if they have negative total assets, employment, sales or tangible fixed assets in any year; or if they have more than 2 million employees in any year.

- We dropped firm-year observations with missing, zero, or negative values for costs of materials, operating revenue and total assets.

- We dropped firms if they do not have a NACE code. 
- We calculated the ratio of the number of employees per million of assets, revenue and revenue/assets. Then we filtered out the top and bottom 0.1 percent of the sample based on these ratios. We did not drop any observations if any of these ratios is missing.

- Further quality checks

- We constructed a variable on the age of the firm, and dropped those firm-year observations with non-positive age.

- We dropped firm-year observations if there are non-positive liabilities. We also calculated liabilities by using two different methods and dropped those if the ratio of these methods is greater than 1.1 or smaller than 0.9 to clean reporting errors.

- We dropped observations if intangible fixed assets are negative, or if fixed assets are zero or negative.

- We dropped observations with missing costs of employees and the number of employees, as well as those with non-positive costs of employees.

- We dropped observations with negative values in a set of variables, such as, current liabilities, non-current liabilities, current asset, loans, creditors, other non-current liabilities, long-term debt, shareholder funds, value added, as well as depreciation and amortization.

- We dropped observations if the ratio of short-term to long-term bank liabilities is greater than 1.1 .

- We further checked some ratios and dropped extreme values as well as winsorized these ratios by dropping the top and bottom 0.1 percent. These ratios include costs of employees to capital, tangible fixed assets to total assets, other shareholder funds to total assets, costs of employees to value added, capital to shareholder funds, and total assets to shareholder funds.

- We finally applied filters on the annual growth rates of sales, operating revenues and number of employees to clean "jumps" in the data caused by reporting errors. Different thresholds were applied to firms based on the size of employment. We dropped firms whose annual growth rates were above these thresholds. 
* For firms with known (lagged) employment:

- For firms with 0-10 employees, drop if employment growth is $>1000 \%$

- For firms with 11-20 employees, drop if employment growth $>500 \%$

- For firms with 21-50 employees, drop if employment growth is $>300 \%$

- For firms with 50-100 employees, drop if employment growth is $>200 \%$

- For firms with $100+$ employees, drop if employment growth is $>100 \%$

* For sales and operating revenue we did the same with respect to company tiers by employment but the threshold is twice as large.

* For firms with missing (lagged) employment, we only drop firms when sales (revenue) growth is greater than $2000 \%$. 


\section{B Additional Results}

Figure B.1: Markup Increase by Weighting Scheme

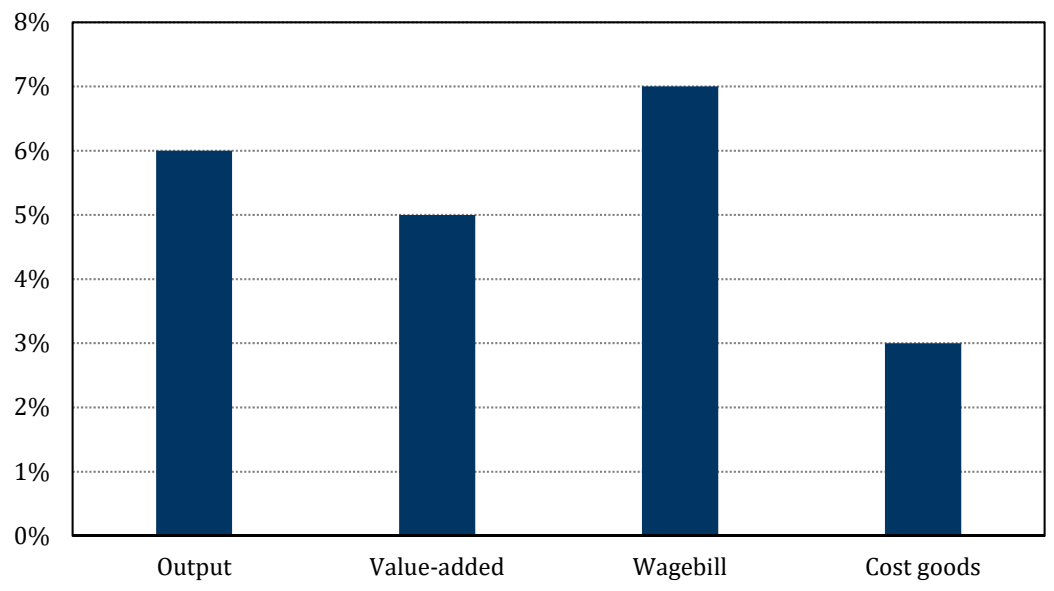

Notes: Authors' calculations based on data from Orbis. The sample includes all countries in the Baseline Sample of Table 1. Firm-level markups are estimated according to equation (6) where $\beta_{s}^{\nu}$ is estimated separately for each country-2-digit sector. Markups weighted by firm's revenue, value added, wage bill, and cost of goods sold.

Figure B.2: Increase in Profitability

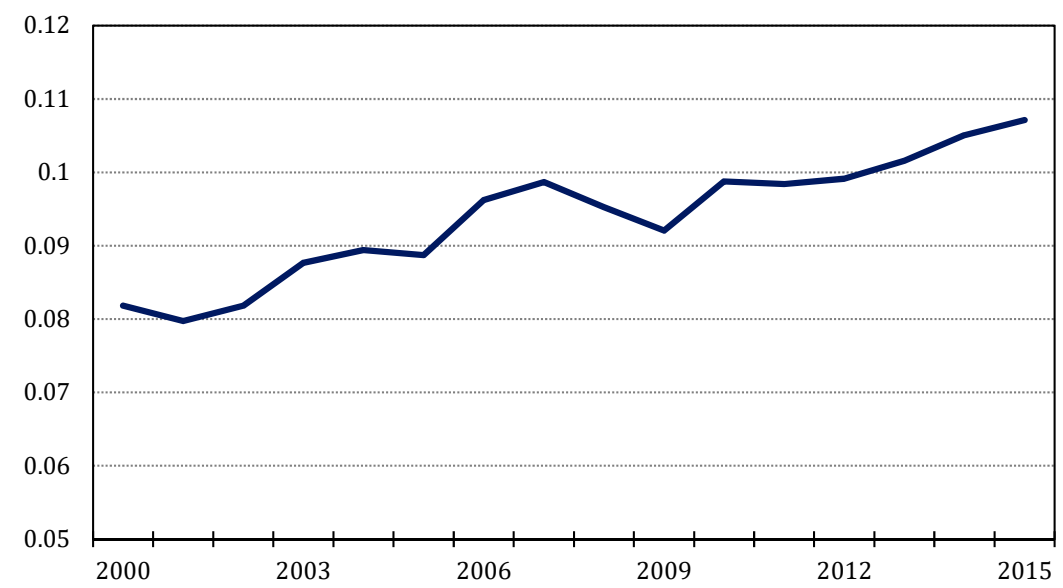

Notes: Authors' calculations based on data from Orbis. The sample includes all countries in the Baseline Sample of Table 1. Firm-level profitability computed as the ratio of EBIT to revenue. 
Figure B.3: Dispersion $\log ($ Markup)

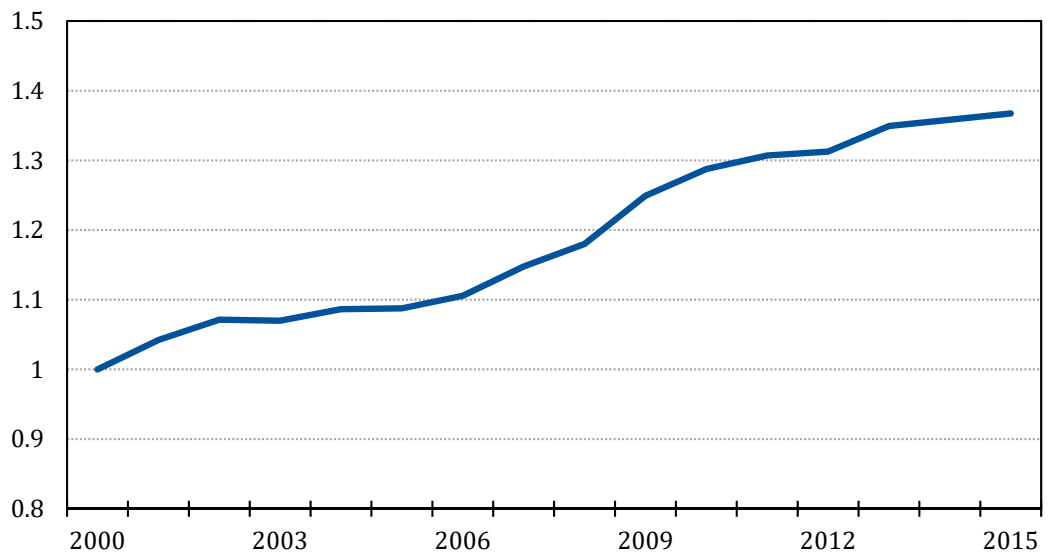

Notes: Authors' calculations based on data from Orbis. The sample includes all countries in the Baseline Sample of Table 1. Dispersion is computed as the standard deviation of firm log-markups within a country-four-digit-industry-year and then averaged over time using time invariant value added country-four-digit-industry weights that add up to one.

Table B.1: Markups and Firm Size: Conditional Correlation

Dependent Variable: log Firm Markup

\begin{tabular}{lcccccc}
\hline \hline & $(1)$ & $(2)$ & $(3)$ & $(4)$ & $(5)$ & $(6)$ \\
\hline & \multicolumn{3}{c}{ Cross-SECTION } & \multicolumn{3}{c}{ Within FIRM } \\
\hline $\log L$ & $-0.047^{* * *}$ & $-0.147^{* * *}$ & $-0.089^{* * *}$ & $-0.085^{* * *}$ & $-0.162^{* * *}$ & $-0.076^{* * *}$ \\
& $(0.000)$ & $(0.001)$ & $(0.001)$ & $(0.001)$ & $(0.002)$ & $(0.002)$ \\
$\log L^{2}$ & & $0.011^{* * *}$ & $0.004^{* * *}$ & & $0.011^{* * *}$ & $0.002^{* * * *}$ \\
& & $(0.000)$ & $(0.000)$ & & $(0.000)$ & $(0.000)$ \\
$\log$ TFP & & & $0.739^{* * *}$ & & & $0.942^{* * *}$ \\
& & & $(0.006)$ & & & $(0.006)$ \\
$\log$ Overhead & & & $-0.012^{* * *}$ & & & $\left(0.018^{* * *}\right.$ \\
& & & $(0.000)$ & & & $(0.000)$ \\
Observations & $4,768,438$ & $4,768,438$ & $2,293,421$ & $4,646,271$ & $4,646,271$ & $2,196,144$ \\
Firm FE & no & no & no & yes & yes & yes \\
Country-Ind-Year FE & yes & yes & yes & yes & yes & yes \\
Cluster & id & id & id & id & id & id \\
\hline
\end{tabular}

Notes: The dependent variable is the log of firm markup recovered for the estimation of a Cobb-Douglas production function and using the cost of goods sold as the flexible input. $\log L$ refers to the $\log$ of employment. $\log T F P$ stands for the $\log$ of total factor productivity. $\log$ Overhead stands for the log of other operating expenses. Columns (1) to (3) do not include firm fixed effects. Columns (4) to (6) include firm fixed effects. Standard errors are clustered at the firm level are reported in parentheses. 


\section{Dynamic OP Decomposition with Entry and Exit}

We accommodate the decomposition of aggregate productivity proposed in Melitz and Polanec (2015) to decompose our estimate of aggregate markup computed as the weighted average of firm markup levels. This section closely follows the derivations in the appendix of Melitz and Polanec (2015) adapting it to the markup notation. They extend the traditional Olley and Pakes (1996) decomposition:

$$
\begin{aligned}
M_{t} & =\sum_{i} s_{i t} \mu_{i t}=\overline{\mu_{t}}+\sum_{i}\left(s_{i t}-\overline{s_{t}}\right)\left(\mu_{i t}-\overline{\mu_{t}}\right) \\
& =\overline{\mu_{t}}+\operatorname{cov}\left(s_{i t}, \mu_{i t}\right)
\end{aligned}
$$

where $M_{t}$ is the firm sales weighted average markup; $s_{i t}$ is the share of firm sales $\left(P_{i t} Y_{i t}\right)$ in total sales in the economy $\left(S_{t}=\sum_{i, t} P_{i t} Y_{i t}\right) ; \bar{\mu}$ is the unweighted average of markups and the second term shows the covariance between firm size $\left(s_{i t}\right)$ and firm markup $\left(\mu_{i t}\right)$.

The extension accommodates firm entry and exit and preserves the features of the original decomposition in providing an additional decomposition between shifts in the distribution of markups

and market share reallocations. Let $s_{G t}=\sum_{i \in G} s_{i t}$ be the aggregate market share of a group $G$ of firms, continuing firms or survivors, entrants and exitors $(G=c, e, x)$. The aggregate markup of each period can be expressed as:

$$
\begin{aligned}
& M_{1}=s_{c 1} M_{c 1}+s_{x 1} M_{x 1}=M_{c 1}+s_{x 1}\left(M_{x 1}-M_{c 1}\right) \\
& M_{2}=s_{c 2} M_{c 2}+s_{e 2} M_{e 2}=M_{c 2}+s_{e 2}\left(M_{e 2}-M_{c 2}\right)
\end{aligned}
$$

The relative change in aggregate markup can be expressed as:

$$
\begin{aligned}
\frac{M_{2}-M_{1}}{\bar{M}} & =\frac{M_{c 2}-M_{c 1}}{\bar{M}}+s_{e 2} \frac{M_{e 2}-M_{c 2}}{\bar{M}}+s_{x 1} \frac{M_{c 1}-M_{x 1}}{\bar{M}} \\
& =\frac{1}{1-\overline{\overline{C o v}}_{c}} \frac{\bar{M}_{c}}{\bar{M}}\left(\frac{\Delta \bar{\mu}_{c}}{\bar{M}_{c}}+\Delta \widetilde{\operatorname{cov}_{c}}\right)+s_{e 2} \frac{M_{e 2}-M_{c 2}}{\bar{M}}+s_{x 1} \frac{M_{c 1}-M_{x 1}}{\bar{M}}
\end{aligned}
$$

where $\widetilde{\operatorname{cov}}=\operatorname{cov}(s, \mu / M)=\operatorname{cov}(s, \mu) / M$ representing the share of aggregate markup $M$ that 
is driven by the correlation between markups and market shares; $\bar{M}=1 / 2\left(M_{1}+M_{2}\right) ; \bar{M}_{c}=$ $1 / 2\left(M_{c 1}+M_{c 2}\right) ; \widetilde{\operatorname{cov}_{c}}=1 / 2\left(\widetilde{\operatorname{cov}_{c 2}}+\widetilde{\operatorname{cov}_{c 1}}\right)$ representing time averages over periods 1 and 2 . Then it is possible to separate the contribution of the continuing firms into two components, one reflecting shifts in the distribution of firm productivity in levels via the change in the unweighted mean $\Delta \bar{\mu}_{c}$ (within-firm markup changes) and the other reflecting the change in the scale-independent covariance (between-firm productivity changes). It is also possible to decompose the contributions of entry and exit in a similar manner:

$$
\begin{aligned}
& \frac{M_{c 1}-M_{x 1}}{\bar{M}}=\frac{1}{1-\overline{\widetilde{c o v}}} \frac{M_{1}}{\bar{M}}\left(\frac{\bar{\mu}_{c 1}-\bar{\mu}_{x 1}}{M_{1}}+\left(\widetilde{\widetilde{c o v}}_{c 1}-\widetilde{\operatorname{cov}}_{x 1}\right)\right) \\
& \frac{M_{e 2}-M_{c 2}}{\bar{M}}=\frac{1}{1-\overline{\overline{\operatorname{cov}_{2}}}} \frac{M_{2}}{\bar{M}}\left(\frac{\bar{\mu}_{e 2}-\bar{\mu}_{c 2}}{M_{2}}+\left(\widetilde{\operatorname{cov}}_{e 2}-\widetilde{\operatorname{cov}}_{c 2}\right)\right)
\end{aligned}
$$

where $\overline{\widetilde{\operatorname{cov}_{1}}}=s_{x 1} \widetilde{\operatorname{cov}}_{c 1}+\left(1-s_{x 1}\right) \widetilde{\operatorname{cov}}_{x 1}$ and $\overline{\widetilde{\operatorname{cov}_{2}}}=s_{e 2} \widetilde{\operatorname{cov}}_{c 2}+\left(1-s_{e 2}\right) \widetilde{\operatorname{cov}}_{e 2}$. 